\title{
Frontal and Parietal Components of a Cerebral Network Mediating Voluntary Attention to Novel Events
}

\section{Citation}

Daffner, K. R., L. F. M. Scinto, A. M. Weitzman, R. Faust, D. M. Rentz, A. E. Budson, and P. J. Holcomb. 2003. "Frontal and Parietal Components of a Cerebral Network Mediating Voluntary Attention to Novel Events." Journal of Cognitive Neuroscience 15, no. 2: 294-313.

\section{Published Version}

10.1162/089892903321208213

\section{Permanent link}

http://nrs.harvard.edu/urn-3:HUL.InstRepos:12997510

\section{Terms of Use}

This article was downloaded from Harvard University's DASH repository, and is made available under the terms and conditions applicable to Other Posted Material, as set forth at http:// nrs.harvard.edu/urn-3:HUL.InstRepos:dash.current.terms-of-use\#LAA

\section{Share Your Story}

The Harvard community has made this article openly available.

Please share how this access benefits you. Submit a story.

\section{Accessibility}




\title{
Frontal and Parietal Components of a Cerebral Network Mediating Voluntary Attention to Novel Events
}

\author{
K. R. Daffner ${ }^{1}$, L. F. M. Scinto ${ }^{1}$, A. M. Weitzman ${ }^{1}$, R. Faust $^{1}$, \\ D. M. Rentz ${ }^{1}$, A. E. Budson ${ }^{1}$, and P. J. Holcomb ${ }^{2}$
}

\begin{abstract}
Despite the important role that attending to novel events plays in human behavior, there is limited information about the neuroanatomical underpinnings of this vital activity. This study investigated the relative contributions of the frontal and posterior parietal lobes to the differential processing of novel and target stimuli under an experimental condition in which subjects actively directed attention to novel events. Eventrelated potentials were recorded from well-matched frontal patients, parietal patients, and non-brain-injured subjects who controlled their viewing duration (by button press) of line drawings that included a frequent, repetitive background stimulus, an infrequent target stimulus, and infrequent, novel visual stimuli. Subjects also responded to target stimuli by pressing a foot pedal. Damage to the frontal cortex resulted in a much greater disruption of response to novel stimuli than to designated targets. Frontal patients exhibited a widely distributed, profound reduction of the novelty $\mathrm{P} 3$ response
\end{abstract}

\section{INTRODUCTION}

Attention to novel events is essential to human behavior and plays a critical role in adaptation and learning (Daffner et al., 1998; Mesulam, 1998; Daffner, Scinto, Weintraub, Guinessey, \& Mesulam, 1994; Hunt \& Levine, 1965; Sokolov, 1963; Berlyne, 1960). The neural components mediating this vital activity require further elucidation. We have demonstrated that damage to the prefrontal cortex in humans leads to diminished voluntary attention to novel events through the disruption of neural processes indexed by the novelty $\mathrm{P} 3$ event-related potential (ERP) response (Daffner, Mesulam, Scinto, et al., 2000). Many attentional functions are subserved by neural networks involving both frontal and posterior components (Corbetta \& Shulman, 2002; Knight, 1997; Mesulam, 1990, 1998; Posner \& Petersen, 1990; Fuster, 1989; Shallice, 1988). Prior research (Knight, 1984, 1996, 1997; Knight, Scabini, Woods, \& Clayworth, 1989) has indicated that under an experimental condition in which subjects are asked to respond to infrequent target

\footnotetext{
${ }^{1}$ Harvard Medical School, ${ }^{2}$ Tufts University
}

and a marked diminution of the viewing duration of novel events. In contrast, damage to posterior parietal lobes was associated with a substantial reduction of both target $\mathrm{P} 3$ and novelty P3 amplitude; however, there was less disruption of the processing of novel than of target stimuli. We conclude that two nodes of the neuroanatomical network for responding to and processing novelty are the prefrontal and posterior parietal regions, which participate in the voluntary allocation of attention to novel events. Injury to this network is indexed by reduced novelty P3 amplitude, which is tightly associated with diminished attention to novel stimuli. The prefrontal cortex may serve as the central node in determining the allocation of attentional resources to novel events, whereas the posterior parietal lobe may provide the neural substrate for the dynamic process of updating one's internal model of the environment to take into account a novel event.

stimuli and attention is only passively directed to novel stimuli that have been defined as task irrelevant, the novelty $\mathrm{P} 3$ response is dependent on the integrity of both the prefrontal cortex and the posterior parietal lobe. Here, we investigate whether the posterior parietal lobe also plays an important role in responding to novel stimuli under a condition in which attention is actively allocated to novel stimuli. Comparing the responses of patients with focal brain lesions to anterior and posterior regions of the brain also provides an opportunity to assess the relative contribution of the frontal and posterior parietal lobes to the differential processing of novel and target stimuli.

Consistent with other theories about the functions of frontal regions (Fuster, 1989; Shallice, 1988; Mesulam, 1986; Mesulam, 2000; Stuss \& Benson, 1986), in our model, the prefrontal cortex is essential for computations about the allocation of attentional resources, and is especially engaged under circumstances in which the behavioral response is not clearly defined in advance. We have suggested (Daffner et al., 1998; Daffner, Mesulam, Scinto, et al., 1999, 2000) that the anterior component of the novelty $\mathrm{P} 3$ response indexes the activity of a 
neural system, dependent on frontal networks, which regulates the allocation of attentional resources to behaviorally relevant events in the environment. In keeping with this view, the amplitude of the $\mathrm{P} 3$ response to novel stimuli predicts subsequent viewing duration (Daffner et al., 1998, 2001; Daffner, Mesulam, Scinto, et al., 2000). Based on this model, we anticipated that damage to the prefrontal cortex would markedly disrupt the novelty $\mathrm{P} 3$ response and reduce attention paid to novel stimuli as measured by viewing duration. In contrast, decisions about resource allocation in response to targets during a relatively simple detection task, as employed in this experiment, do not appear to require the engagement of frontal systems (Corbetta \& Shulman, 2002; Knight, 1997). Thus, we anticipated that damage to frontal lobes would have a limited impact on the target P3 response.

Our predictions about the impact of damage to the prefrontal cortex are consistent with the ones that could be derived from the recently proposed model of attention by Corbetta and Shulman (2002), which is largely based on a review of pertinent literature in functional neuroimaging. They suggest that the ventral prefrontal cortex participates as a "circuit breaker" to ongoing task-related activities and mediates the reorientation of attention to unexpected events. Furthermore, the dorsal prefrontal regions participate in the controlled (topdown) aspects of directing attentional set. This model also leads to the prediction that lesions in the frontal lobes would markedly disrupt responses to novel stimuli, especially under an experimental condition in which subjects must not only orient to unexpected visual stimuli, but also decide how long to look at them.

The Corbetta-Shulman model of attention, like the earlier one proposed by Posner and Petersen (1990), posits a central role for the parietal lobe in the topdown control of focal attention in the selection of designated targets (Shulman, Ollinger, Linenweber, Petersen, \& Corbetta, 2001; Corbetta, Kincade, Ollinger, McAvoy, \& Shulman, 2000). According to Corbetta et al. (2000) and Shulman et al. (2001), the detection of infrequent target stimuli reflects the interaction between top-down attentional control mechanisms mediated by superior parietal regions and bottom-up, stimulus-driven processing dependent on the temporalparietal junction. Their model suggests that the inferior parietal region (temporal-parietal junction) also contributes to the circuit-breaker activity noted above, which allows for the reorienting of attention and detection of unexpected novel events. This model predicts that damage to parietal regions would disrupt the processing of both anticipated target and unexpected novel stimuli and would manifest in the current experiment as an attenuation of the novelty and especially the target $\mathrm{P} 3$ response.

Several lines of evidence suggest that it is unlikely that the P3 response mediated by parietal lobes simply reflects the detection of target or novel stimuli. It has been shown that subjects can identify and behaviorally respond to a target before the occurrence of a target P3 wave (Picton, 1992). Patients with parietal lobe lesions can exhibit markedly abnormal target P3 waves and yet still be able to detect target events (Knight, 1997). Event-related potentials that occur earlier than the $\mathrm{P} 3$ wave, such as the $\mathrm{N} 2$ response, have been associated with the detection and categorization of behaviorally relevant events (Pritchard et al., 1991; Naatanen, Picton, McCallum, Zappoli, \& Denoth, 1986), suggesting that the P3 response indexes a component of information processing other than detection. Finally, the amplitude of the target $\mathrm{P} 3$ response is much more sensitive to the infrequency and unexpectedness of a target event than to the mere occurrence of a designated target (Picton, 1992; Johnson, 1986; Donchin, 1981; DuncanJohnson \& Donchin, 1977). An adequate formulation of the function of the parietal lobe in the $\mathrm{P} 3$ response needs to account for these findings.

Our model of the role of the parietal cortex is consistent with the one that has been formulated by Mesulam (1981, 1990). He has argued that the posterior parietal cortex serves as a critical gateway for accessing and integrating information that allows for the development of a highly processed internal model about the environment. We hypothesize that the posterior component of the $\mathrm{P} 3$ response to target and novel stimuli indexes the neural activity associated with updating this model in response to a behaviorally significant event (Donchin, 1981; Donchin \& Coles, 1988). Damage to the parietal cortex will lead to the degradation of this process and to the attenuation of the target and novelty $\mathrm{P} 3$ response.

In the current study, a group of patients with chronic infarctions centered in the posterior parietal lobe were compared to a group of patients whose strokes were centered in the prefrontal cortex and to a group of matched normal controls, thus extending work previously reported (Daffner, Mesulam, Scinto, et al., 2000). ERPs were recorded from scalp electrode sites while subjects viewed a series of line drawings that included a frequent, repetitive background stimulus, an infrequent target stimulus, and infrequent novel stimuli (e.g., fragmented or "impossible" objects). Task instructions emphasized that the study was investigating how people look at different kinds of visual stimuli. Subjects controlled viewing duration by a button press that led to the onset of the next stimulus and served as a measure of visual attention (Daffner, Scinto, Weintraub, Guinessey, \& Mesulam, 1992; Daffner et al., 1998; Loftus \& Mackworth, 1978; Berlyne, 1960). Subjects also responded to target stimuli by pressing a foot pedal. Based on previous work and our model of the functional roles of the prefrontal and posterior parietal regions, we hypothesized that compared to normal control subjects ("controls"), parietal lobe ("parietal") patients would exhibit diminished $\mathrm{P} 3$ response to both 


\begin{tabular}{|c|c|c|c|c|c|}
\hline & $\begin{array}{c}\text { Normal Controls } \\
\quad(n=20)\end{array}$ & $\begin{array}{l}\text { Frontal } \\
\qquad(n=\end{array}$ & $\begin{array}{l}\text { Patients } \\
\text { 10) }\end{array}$ & $\begin{array}{l}\text { Parietal Patients } \\
(n=7)\end{array}$ & $p$ Value $^{\mathrm{a}}$ \\
\hline Age (years) & $68.3(7.3)$ & 62.3 & $(15.7)$ & $64.6(14.0)$ & $n s$ \\
\hline Education (years) & $16.2(3.1)$ & 15.1 & $(2.5)$ & $13.0 *(2.1)$ & $<.05$ \\
\hline Estimated IQ & $121.2(5.8)$ & 116.4 & $(10.0)$ & $117.9(9.4)$ & ns \\
\hline MMSE $(0-30)$ & $29.0(1.0)$ & 27.0 & $(3.7)$ & $27.6(3.0)$ & $n s$ \\
\hline MAE Naming (education adjusted) (0-60) & $57.0(2.9)$ & 52.1 & $(7.4)$ & $53.9(8.3)$ & ns \\
\hline Apraxia $(0-60)$ & $59.9(.7)$ & 59.0 & $(2.2)$ & $59.7(.5)$ & $n s$ \\
\hline Zung score $(20-80)$ & $30.4(4.9)$ & 37.9 & $(11.4)$ & $37.0(9.7)$ & $n s$ \\
\hline \multicolumn{6}{|l|}{ Apathy scores } \\
\hline Self-report scale $(0-42)$ & $5.7(3.5)$ & $13.1^{*}$ & $(8.3)$ & $8.6(7.7)$ & $<.05$ \\
\hline Informant-based inventory $(0-40)$ & $5.7(4.3)$ & $17.2^{* *}$ & $(6.0)$ & $15.2(6.6)$ & $<.005$ \\
\hline
\end{tabular}

Values given are mean $( \pm S D)$; ns $=$ not significant.

${ }^{a}$ Overall analysis across all three groups.

$* p<.05$ vs. NC.

$* * p<.01$ vs. NC.

$* * * p<.001$ vs. NC.

target and novel stimuli, but that the disruption would be more extensive when responding to target than to novel stimuli. In contrast, we expected that frontal lobe ("frontal") patients would exhibit a more profoundly impaired response to novel than to target stimuli.

\section{RESULTS}

\section{Subject Characteristics}

Frontal patients, parietal patients, and controls did not differ significantly in terms of age, estimated IQ (Raven, Court, \& Raven, 1995; Ryan and Paolo, 1992; Nelson \& O'Connell, 1978), Mini Mental State Examination score (Folstein, Folstein, \& McHugh, 1975), Multilingual Aphasia Examination (education adjusted) Naming score (Benton \& DeS.Hamsher, 1983), Apraxia score (Kertesz, Ferro, \& Shewan, 1984), or Zung Depression Scale scores (Zung, 1965) (Table 1). Parietal patients had fewer years of education than controls $(p<.02)$. Patients with right-hemisphere lesions exhibited minimal evidence of neglect on the Line Bisection Test (Schenkenberg, Bradford, \& Ajax, 1980). The seven frontal patients with right-sided lesions only missed an average of $1.6 \%( \pm 2.7)$ of the 18 lines presented, and deviated from bisecting the midline an average of $4.1 \%$ $( \pm 4.5)$ to the right of center. The six parietal patients with right-sided lesions only missed $1.9 \%( \pm 4.5)$ of lines and deviated from midline an average of $3.7 \%( \pm 3.9)$ to the left of center. Controls missed none of the lines and deviated from midline an average of $4.8 \%( \pm 3.0)$ to the left of center.
There were significant differences among the groups in terms of apathy as measured by self-report on the Apathy Scale (Starkstein, Fedoroff, Price, Leiguarda, \& Robinson, 1993) $(p<.03)$ and informant-based judgments on the Personality and Behavioral Inventory (Daffner, Mesulam, Cohen, \& Scinto, 1999) $(p<$ .002). Frontal patients were more apathetic than controls (Apathy Scale, $p<.008$; Personality and Behavioral Inventory, $p<.0005)$, although their mean severity level was in the mild range (Table 1). Apathy level for parietal patients was between that of controls and frontal patients, but the difference between parietal patients and the other two groups was not statistically significant.

\section{P3 Data}

Figure 1 presents the grand average ERP plots for the group of control subjects, frontal patients, and parietal patients. Figure 2 shows bar graphs of the P3 amplitudes at midline sites for each group. Figure 3 illustrates the voltage difference maps of the $\mathrm{P} 3$ amplitude of controls minus frontal patients, of controls minus parietal patients, and of parietal patients minus frontal patients for background, novel, and target stimuli.

\section{Overview of the P3 Response Across Subject Groups}

Relative to controls, the $\mathrm{P} 3$ response of frontal patients to novel stimuli was markedly reduced throughout the scalp (Figures 1, 2, and 3A). The novelty P3 response of 
frontal patients exhibited a much narrower peak than controls or parietal patients (Figure 1). The amplitude of the novelty $\mathrm{P} 3$ response of parietal patients was between that of controls and frontal patients, except at the most posterior sites, where it was as small as that of frontal patients (Figures 2A and B, 3B and $\mathrm{C}$ ). The greatest difference in the novelty $\mathrm{P} 3$ amplitude between parietal patients and controls was observed in the ipsilesional

\section{Normal Controls}
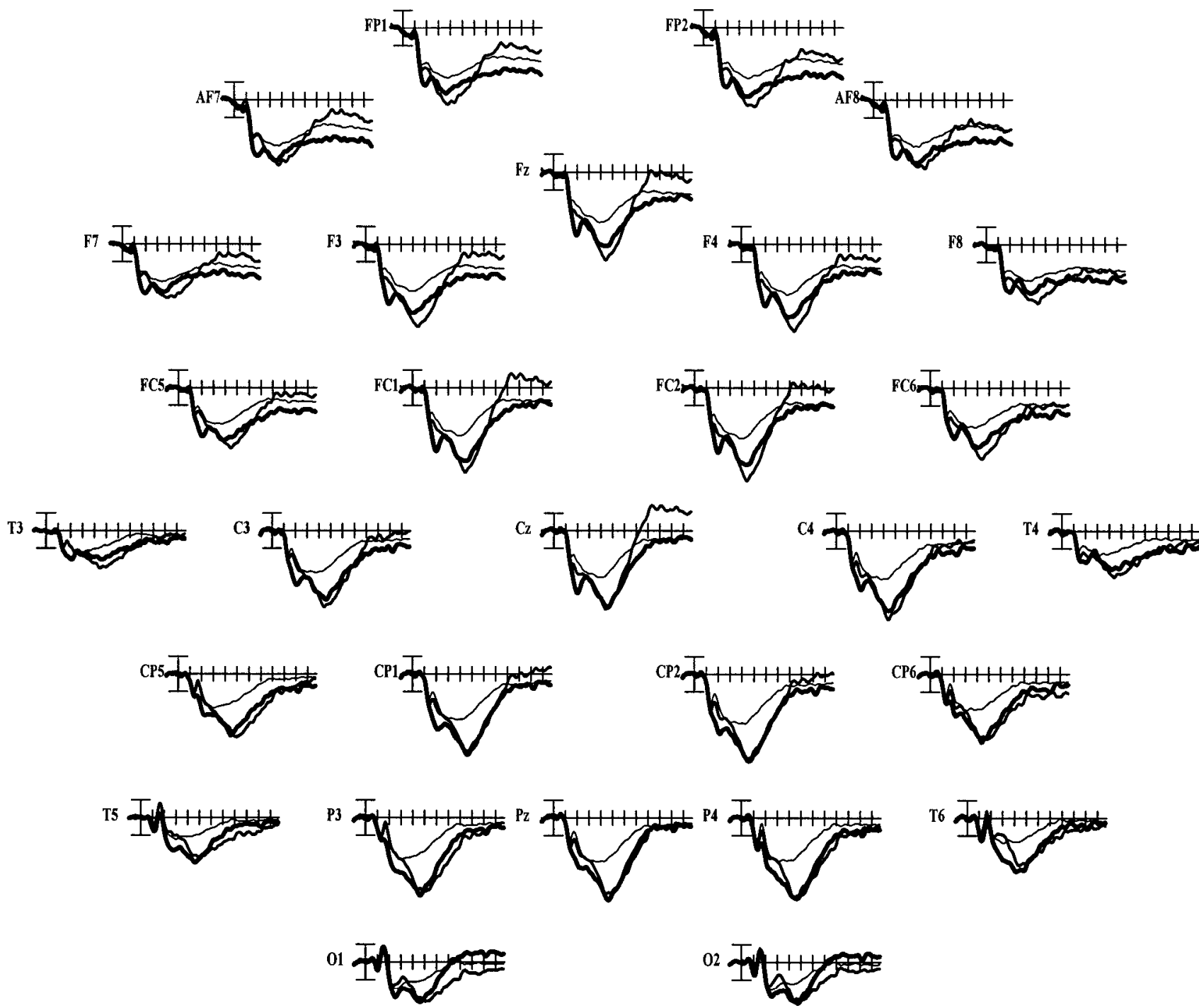

${ }^{3 \mu \nu} \mathrm{T}_{2004006008001000}$

Figure 1. Grand average ERP plots for midline and lateral sites in response to background stimuli (thin lines), target stimuli (thick lines), and novel stimuli (bold lines) for (A) normal control subjects, (B) frontal lobe patients, and (C) parietal lobe patients. For stroke patients, ERPs ipsilateral to the lesion are shown on the right side of the figure. 


\section{Frontal Patients}
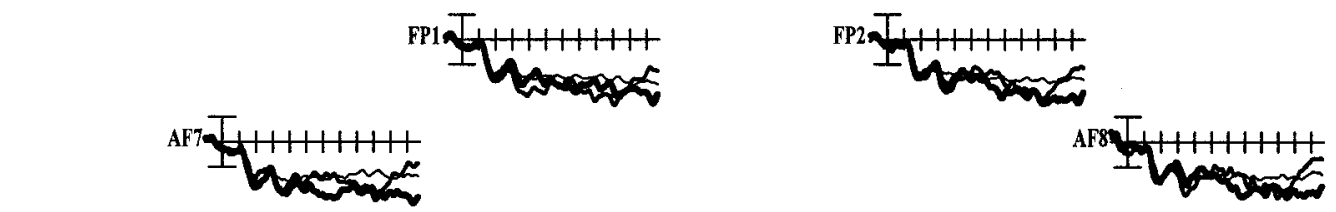

Fi
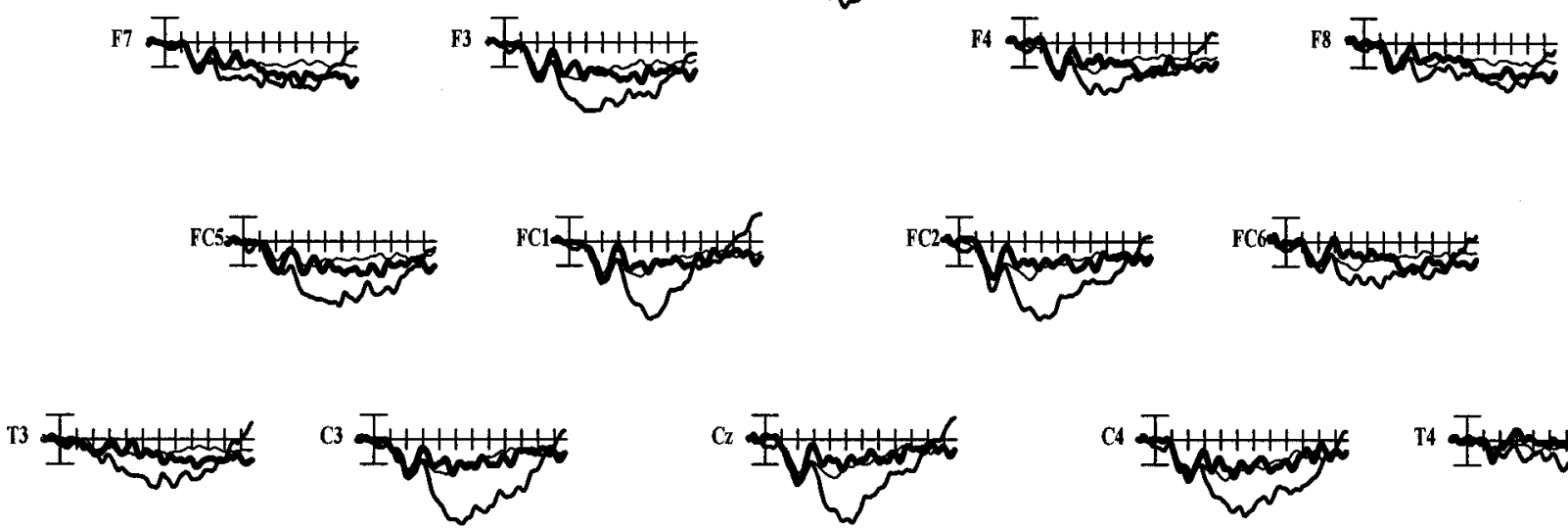

14 T.
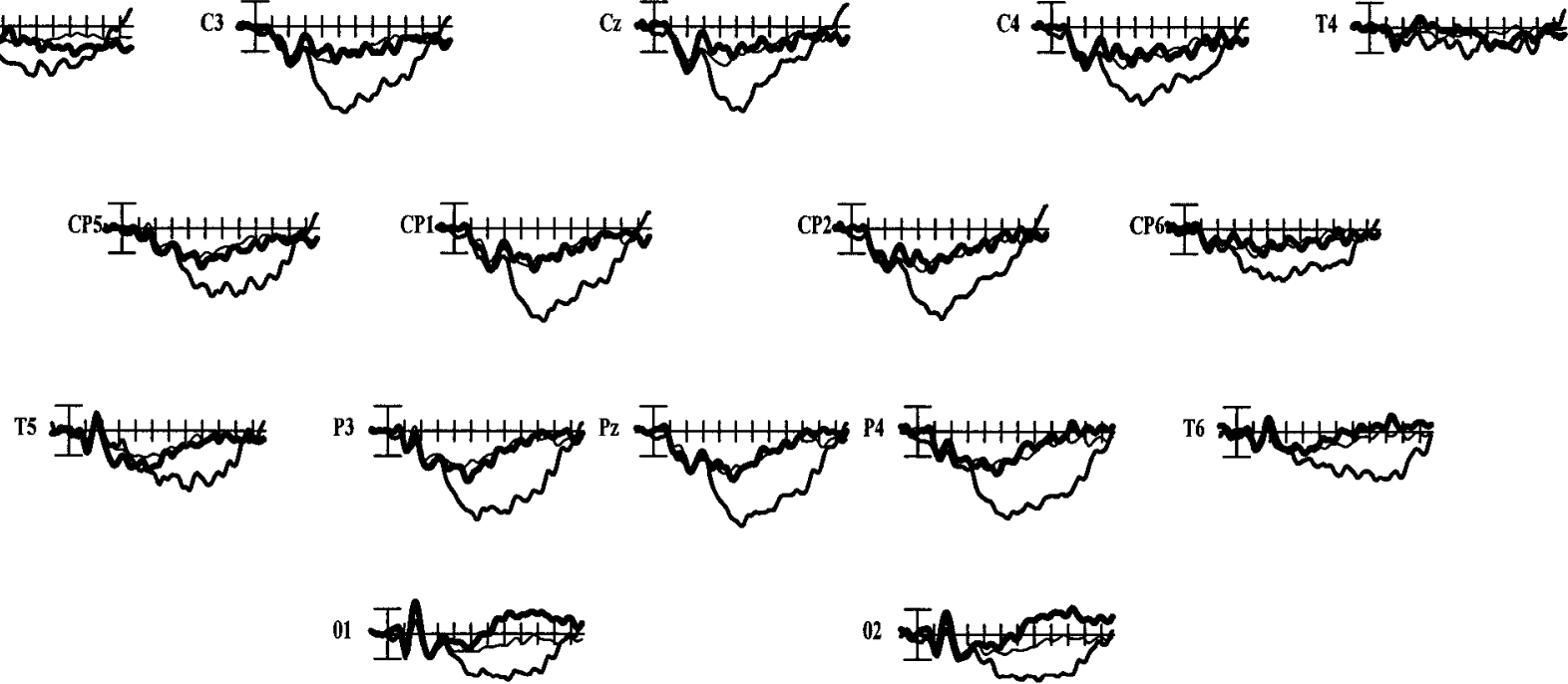

$$
{ }^{3 \mu v} \mathrm{~T}_{2004006008001000}^{+\mathrm{H}}
$$

Figure 1. (continued)

posterior quadrant (Figure 3B). For target stimuli, the P3 response of frontal patients was relatively well preserved, except at the most anterior sites (especially on the ipsilesional side) (Figures $2 \mathrm{~A}$ and $\mathrm{B}, 3 \mathrm{~A}$ ), whereas the target $\mathrm{P} 3$ response of parietal patients was reduced throughout the scalp (Figures $2 \mathrm{~A}$ and B, 3B).

\section{Frontal Patients vs. Controls}

Overall, the P3 amplitude of frontal patients was smaller than that of controls (main effect of group, midline: $F(1,28)=19.02, p<.000005$; lateral: $F(1,28)=27.13$, $p<.000005)$. The differences in $\mathrm{P} 3$ response to the 


\section{Parietal Patients}
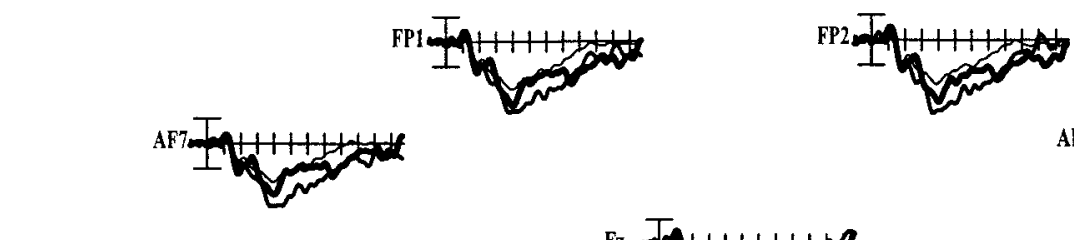

(1)
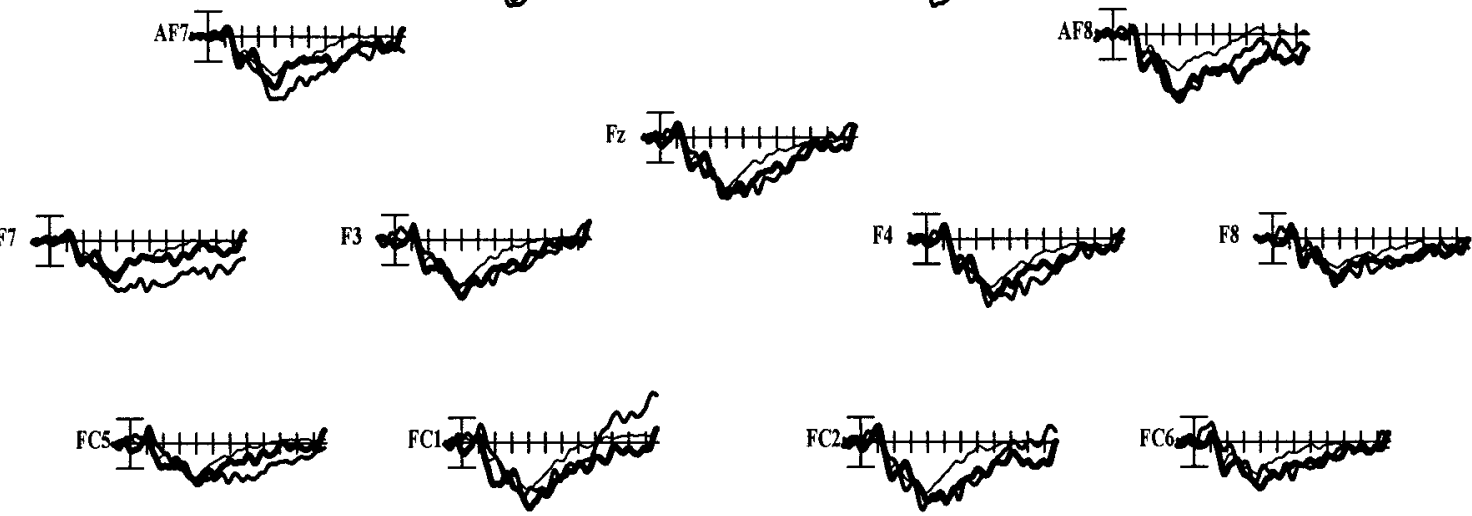

T3 Iryot
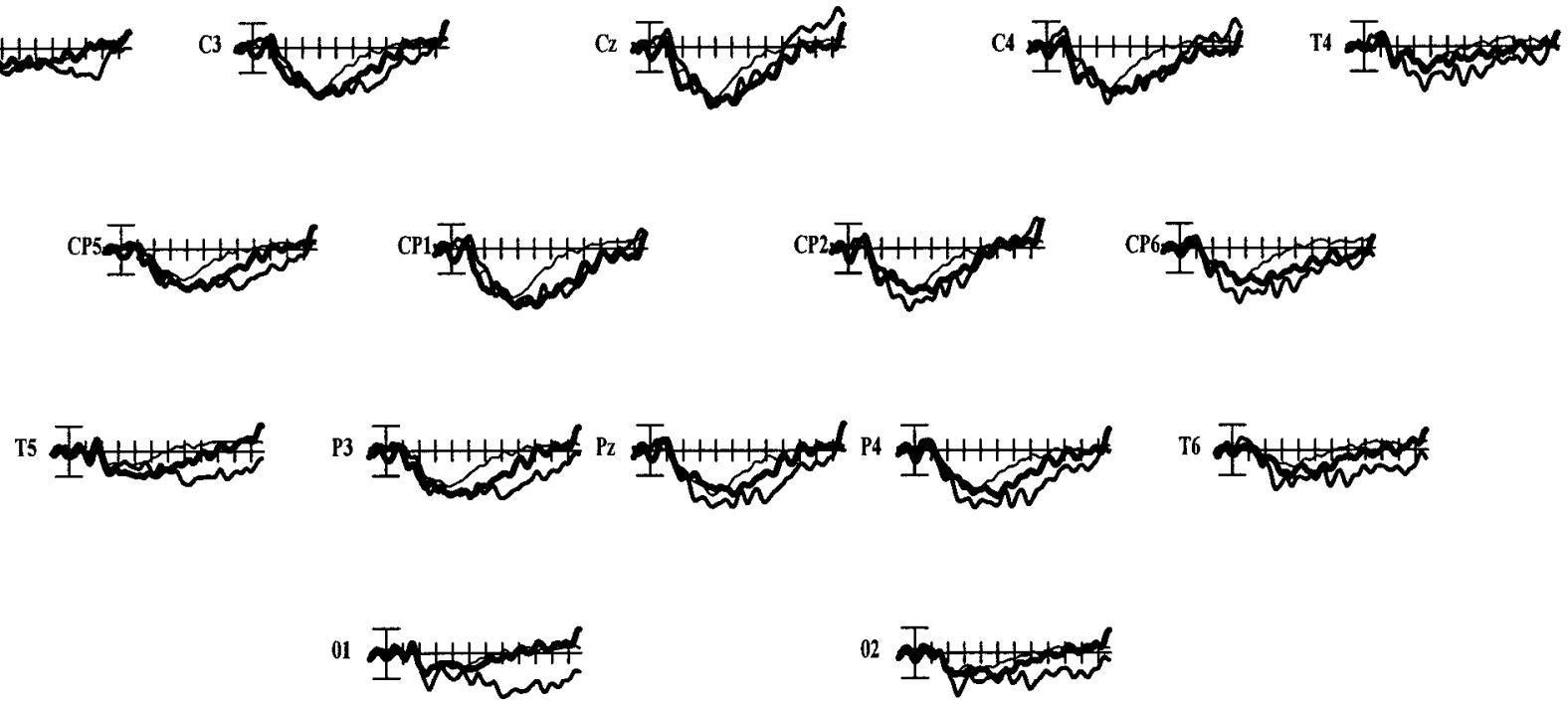

22

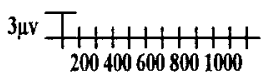

Figure 1. (continued)

three stimulus types varied between the groups (stimulus type by group interaction, midline: $F(2,56)=8.19$, $p<.002$; lateral: $F(2,56)=7.40, p<.004)$. For controls, the amplitude of the P3 response to novel and target stimuli was of similar magnitude (midline: $p>.9$; lateral: $p>.4$ ), both of which were larger than to that of background stimuli (midline and lateral: $p s<.001$ ). In contrast, for frontal patients, P3 response to novel stimuli was of similar magnitude to background stimuli (midline: $p>.6$; lateral: $p>.8$ ), both of which were 


\section{P3 mean amplitude at midline electrode sites}

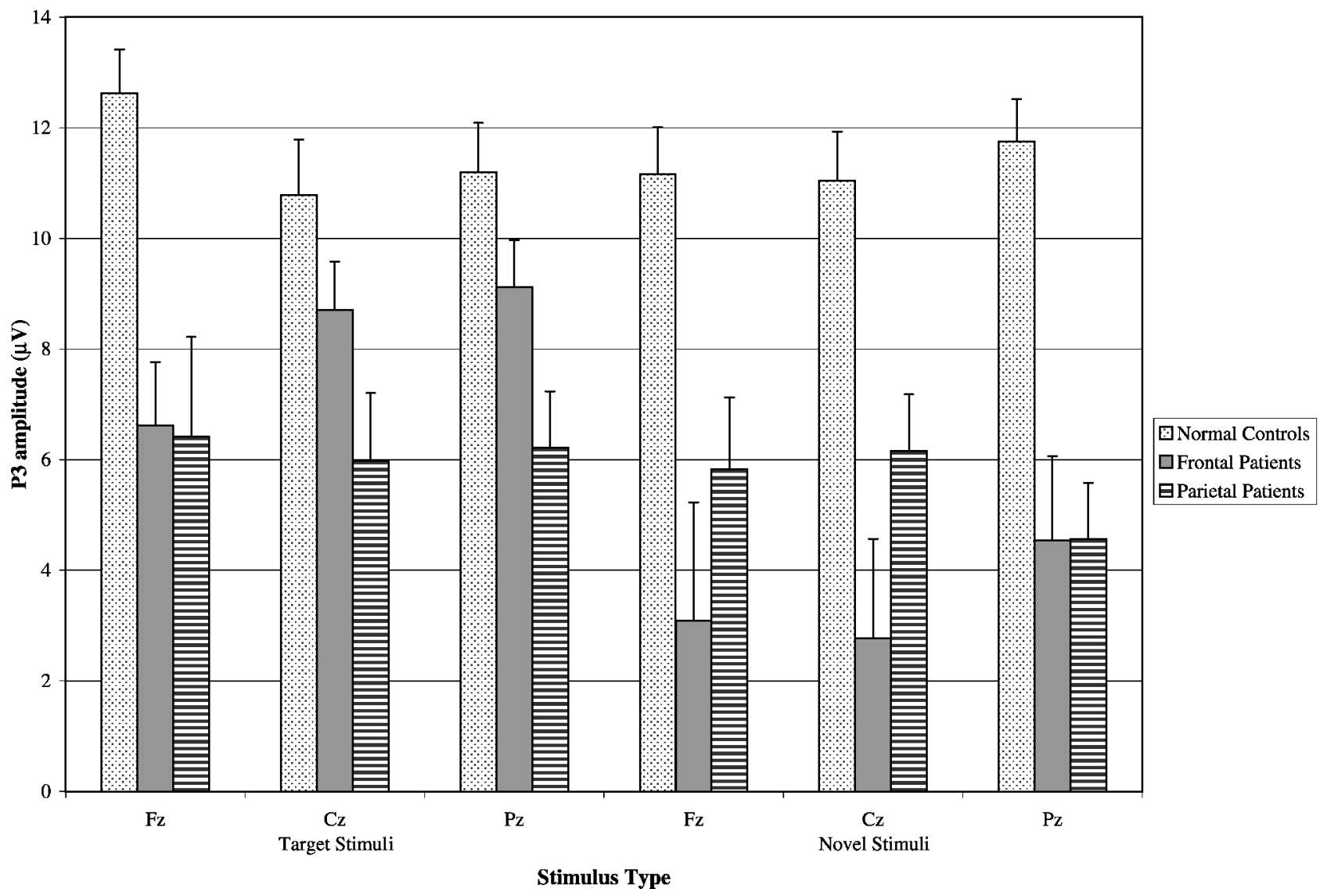

P3 difference waves at midline sites

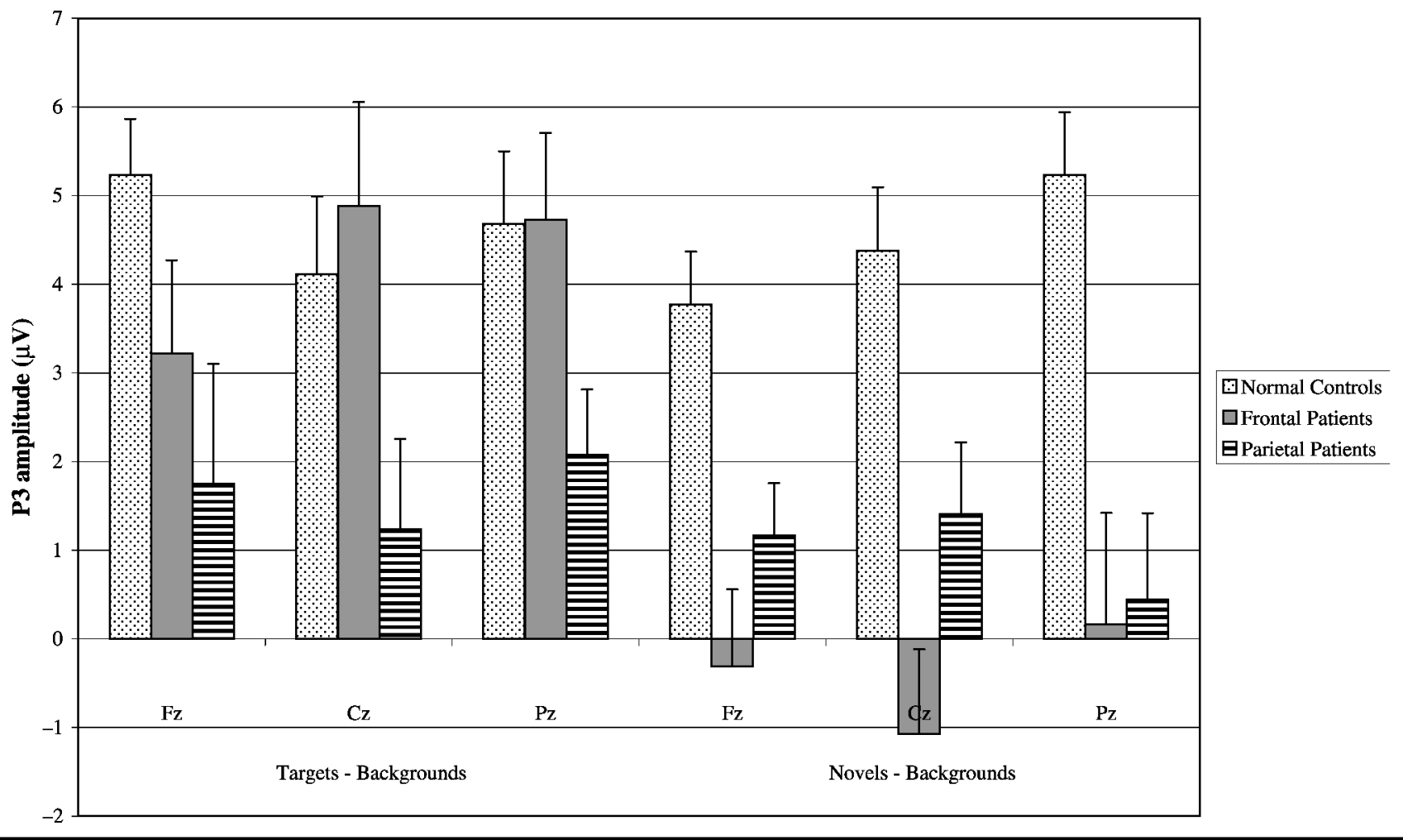


smaller than to target stimuli (midline: $p$ s < .008; lateral: $p s<.01)$. The difference between controls and frontal patients in $\mathrm{P} 3$ amplitude was larger in response to novel stimuli than target stimuli (midline: $F(1,28)=7.62$, $p<.02$; lateral: $F(1,28)=4.31, p<.05)$. To further illustrate this point, an analysis was done on the difference waves derived from subtracting the P3 amplitude to background stimuli from both the P3 amplitude to novel stimuli and the P3 amplitude to target stimuli (i.e., novelty - background, and target - background) (Figure 2B). There was a substantial difference between frontal patients and controls in response to novel events (midline: $F(1,28)=18.40, p<.0002$; lateral $F(1,28)=20.66, p<.0001)$, but no difference between groups in response to target stimuli (midline: $F(1,28)=.11, p>.7$; lateral: $F(1,28)=1.88, p>.18)$.

The latency of $\mathrm{P} 3$ responses of frontal patients was significantly delayed compared to controls (main effect of group, $F(1,28)=10.13, p<.005)$, and was of similar magnitude for all stimulus types and across all midline locations (no stimulus type $\times$ group, or stimulus type $\times$ group $\times$ electrode site interactions) (Table 2). For both groups, the P3 latency varied across stimulus types $[F(2,56)=13.34, p<.00005]$, with P3 latency to background stimuli being shorter than to novel stimuli $[F(1,28)=8.69, p<.007]$, and to target stimuli $[F(1,28)=38.75, p<.000005]$, with a trend for an earlier P3 latency to novel than target stimuli $[F(1,28)=3.16, p=.086]$.

The reduction of $\mathrm{P} 3$ amplitude in frontal patients as compared to controls had a different scalp distribution for novel and target stimuli (stimulus type $\times$ electrode site $\times$ group interaction, midline: $F(2,56)=6.90$, $p<.004$; lateral: $F(24,408)=3.59, p<.002$ ). (For an illustration, see Figure 3A.) The novelty P3 was smaller for frontal patients than controls across all midline locations (no group $\times$ electrode site interaction) and at both fronto-central and centro-parietal sites laterally $($ group $\times$ electrode site interaction, $F(12,336)=3.50$, $p<.03)$. In contrast, for frontal patients, the reduction in target $\mathrm{P} 3$ was limited to anterior sites (group $\times$ electrode site interaction, midline: $F(2,56)=6.51, p<.006$; lateral: $F(12,336)=2.64, p<.05)$, especially over the ipsilesional hemisphere (group $\times$ hemisphere interaction, $F(1,28)=9.37, p<.005)$.

\section{Parietal Patients vs. Controls}

Overall, the $\mathrm{P} 3$ response of parietal patients was smaller than that of controls (main effect of group, midline: $F(1,25)=18.34, p<.000005$; lateral: $F(1,25)=21.45$, $p<.000005)$. P3 amplitude in response to the three stimulus types also differed between parietal patients and controls (stimulus type $\times$ group interaction, midline: $F(2,50)=3.71, p<.04$; lateral: $F(2,50)=3.29$, $p=.05)$, although the pattern was distinct from that of the frontal patients. As noted above, for controls, there was no difference in P3 amplitude to novel and target stimuli, both of which were larger than to background stimuli. In contrast, for parietal patients, there was no difference at midline sites in overall P3 response to all three stimulus types. At lateral sites there was a main effect for stimulus type $[F(2,12)=$ 6.24, $p<.02]$. P3 response to background stimuli was smaller than to target stimuli $[F(1,6)=14.44$, $p<.01]$, and marginally smaller than to novel stimuli $[F(1,6)=3.88, p=.096]$, with no difference between P3 response to novel and target stimuli. The magnitude of the difference between controls and parietal patients was similar for target and novel stimuli (no group $\times$ stimulus type interaction for target and novel stimuli), a pattern that was confirmed by analyzing the difference waves (target - background and novel background) across the two groups. P3 latency did not differ between parietal patients and controls across stimulus types and midline electrode sites (Table 2) (no effect of group; no group $\times$ stimulus type nor group $\times$ stimulus type $\times$ electrode site interactions). For both groups, the P3 latency differed across stimulus types $[F(2,50)=24.08, p<.000005]$, with the $\mathrm{P} 3$ latency to background stimuli being shorter than to novel stimuli $[F(1,25)=19.84, p<.0002]$, which in turn was shorter than to target stimuli $[F(1,25)=6.33$, $p<.02]$.

The reduction of $\mathrm{P} 3$ amplitude in parietal patients relative to controls had a different scalp distribution for novel and target stimuli (midline, stimulus type $\times$ electrode site $\times$ group interaction $[F(2,50)=4.14$, $p<.03]$; lateral, stimulus type $\times$ electrode site $\times$ hemisphere $\times$ group interaction $[F(12,300)=3.06$, $p<.009]$ ) (Figure 3B). At midline sites, the reduction of the novelty $\mathrm{P} 3$ observed in parietal patients was largest at $\mathrm{Pz}$, whereas the reduction of the target $\mathrm{P} 3$ was evenly distributed across locations. At lateral sites, the reduction of the novelty $\mathrm{P} 3$ was largest over the ipsilesional posterior quadrant, whereas the reduction of target P3 was observed across the entire scalp.

\section{Parietal Patients vs Frontal Patients}

There were no overall differences in P3 amplitude between frontal and parietal patients (no main effect of group). However, P3 response to novel and target stimuli differed for the two patient groups at midline

Figure 2. Bar graphs of midline sites for each subject group of (A) P3 amplitude in response to novel and target stimuli and (B) P3 amplitude difference waves (novel stimuli - background stimuli and target stimuli - background stimuli). 
sites (stimulus type $\times$ group interaction, midline: $F(1,15)=5.53, p<.04)$, with a similar trend at lateral locations $(F(1,15)=3.32, p=.088)$. This interaction reflected the fact that the novelty $\mathrm{P} 3$ amplitude was smaller for frontal patients than parietal patients, whereas the target P3 amplitude was smaller for parietal patients than frontal patients. P3 latency was longer for frontal patients than parietal patients (Table 2) (main effect of group, $F(1,15)=5.72, p<.04)$ across all stimulus types and midline electrode sites (no group $\times$ stimulus type or group $\times$ stimulus type $\times$ electrode site interaction). Differences between parietal patients and frontal patients in P3 amplitude had a distinct scalp distribution for novel and target stimuli (stimulus type $\times$ electrode site $\times$ group interaction, midline: $F(2,30)=3.82, p=.059$; lateral: $F(12,180)=3.75$, $p<.02)$. At midline and lateral sites, frontal patients tended to have a smaller novelty $\mathrm{P} 3$ response than parietal patients at fronto-central locations, whereas parietal patients tended to have a smaller target P3 response than frontal patients at centro-parietal sites (Figure 3C).

\section{Behavioral Data}

There were no differences among groups in how long subjects looked at background stimuli. The groups differed in the amount of time they spent looking at novel stimuli $[F(2,36)=3.18, p=.05]$. Frontal patients viewed novel stimuli for less time than controls $[F(1,28)=5.02$, $p<.04]$, and parietal patients $[F(1,16)=5.89, p<.03]$ (Table 3). All groups spent more time viewing novel than background stimuli (main effect of stimulus type, $F(1,34)=25.44, p<.00005)$, although the effect was more robust in the control group $(F(1,19)=22.60, p<$ $.0002)$ than the frontal group $(F(1,9)=10.28, p<.05)$ and the parietal group $(F(1,6)=6.75, p<.05)$ (stimulus type $\times$ group interaction, $F(2,34)=3.17, p=.05)$.

Subjects varied in the rate at which they moved through the stimulus set. Response times in stroke subjects may have been affected by nonspecific alterations in speed of motor or cognitive processing. To help control for these factors, a measure of proportionality (viewing duration novels $\div$ viewing duration backgrounds) was constructed. This ratio is particularly appropriate because the novel stimuli are defined in terms of their deviance from background stimuli. The three groups differed significantly in their ratio of viewing duration of novels/backgrounds $[F(2,36)=$ $5.99, p<.006]$ (Figure 4 ). The ratio was significantly smaller for frontal patients than controls $[F(1,29)=$ 13.28, $p<.002]$. The ratio for parietal patients was between that of controls (for which there was no significant difference) and frontal patients (for which there also was no significant difference).

In terms of responses to target stimuli, there were no significant group differences in reaction time, percent correct hits, number of false alarms, or ratio of viewing duration of targets to viewing duration of backgrounds (Table 3). The amount of time subjects spent looking at target stimuli differed across groups $[F(2,36)=3.47$, $p<.05]$, reflecting the fact that the target viewing duration was longer for parietal patients than controls $[F(1,26)=6.77, p<.02]$.

\section{Correlations Between Novelty P3 Amplitude and Viewing Durations}

Because our model suggests that the novelty P3 response reflects neural activity that allocates attentional resources to novel events, we examined the correlation between novelty $\mathrm{P} 3$ amplitude and the ratio of viewing duration of novel stimuli to viewing duration of background stimuli across various subject groups (see Table 4). The Spearman's rho ranged from .54 to .75 for all groups except for patients with frontal lobe lesions for whom no correlation was observed.

\section{DISCUSSION}

The process of orienting and attending to novel events facilitates adaptation to a rapidly changing environment and probably has contributed to the evolution of the mammalian brain (Mesulam, 1998; Daffner et al., 1994, 1998; Hunt \& Levine, 1965; Sokolov, 1963; Berlyne, 1960). Clinical observations of a wide range of neurological and psychiatric conditions have also pointed to a disruption of novelty-seeking behavior that can dramatically undermine the quality of life of patients (Daffner et al., 2001; Craig et al., 1996; Marin, 1990; Mesulam, 1986). Despite the importance to human behavior of appropriately responding to novelty, there is limited information about its neuroanatomical underpinnings.

Event-related potentials have been a major tool in the study of the human brain's response to novelty. Previous studies have almost always employed a "novelty oddball paradigm," in which a subject's task is to identify infrequent target stimuli that are presented in a sequence that has frequent, repetitive background stimuli. Infrequent novel stimuli are also presented that are "task irrelevant" and to be ignored. Within this context, the P3 response to these novel stimuli (i.e., the novelty P3) has been interpreted as reflecting an involuntary, automatic process (Knight \& Nakada, 1998; Knight \& Scabini, 1998) involved in the orienting of attention to and/or the detection of deviant stimuli (Baudena, Halgren, Heit, \& Clarke, 1995; Hillyard, Picton, Plum, Mountcastle, \& Geiger, 1987; Knight, 1984; Rohrbaugh, Parasuraman, \& Davies, 1984; Naatanen, Gaillard, Gaillard, \& Ritter, 1983; Snyder \& Hillyard, 1976; Courchesne, Hillyard, \& Galambos, 1975; Squires, Squires, \& Hillyard, 1975; Roth, 1973; Ritter, Vaughan, \& Costa, 1968). Using this type of novelty oddball paradigm, researchers have studied the cortical contributions to the surface novelty 


\section{P3}
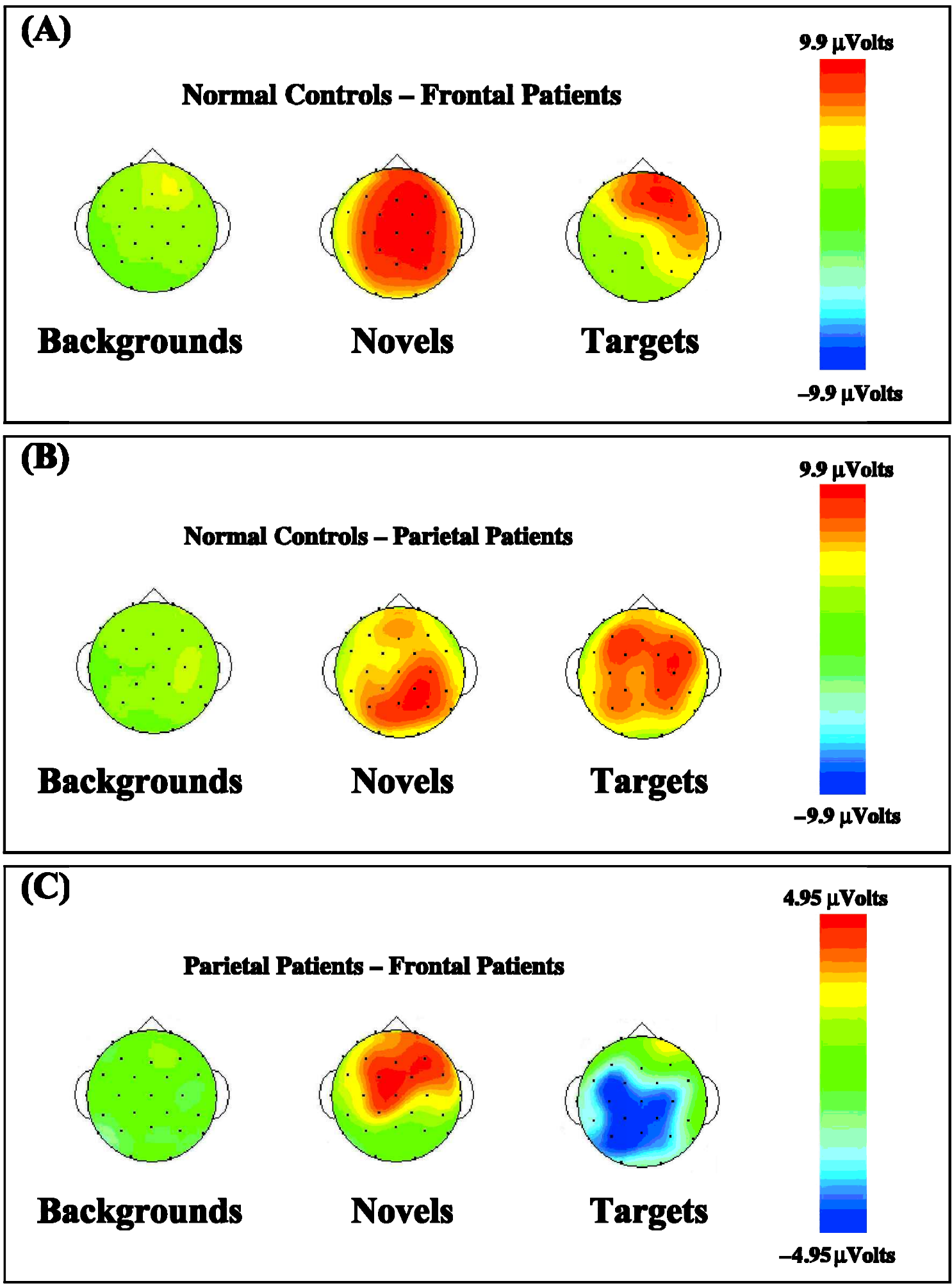

Figure 3. Voltage-difference maps. (A) P3 amplitude of normal control subjects minus frontal lobe patients for each stimulus type, (B) P3 amplitude of normal control subjects minus parietal lobe patients, and (C) P3 amplitude of parietal lobe patients minus frontal lobe patients. Note that the range of the scale used in (C) is half that of (A) and (B). Responses ipsilateral to the lesion in stroke patients are shown on the right side of the scalp. 
Table 2. P3 Latency (in Milliseconds) at Midline Sites

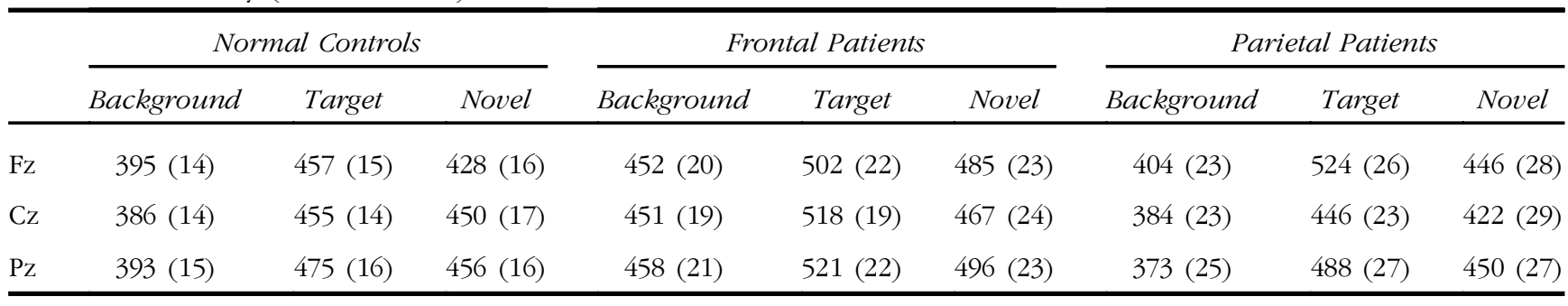

Values given are mean $( \pm S E M)$.

P3 response by investigating patients with focal lesions (Daffner, Mesulam, Scinto, et al., 2000; Knight, 1984, 1996, 1997; Knight et al., 1989), patients undergoing evaluation with depth electrodes (Baudena et al., 1995; Halgren et al., 1995; Alain, Richer, Achim, \& Saint Hilaire, 1989), and non-brain-damaged subjects using ERP source analysis (Spencer, Dien, \& Donchin, 1999; Mecklinger \& Ullsperger, 1995) or functional neuroimaging techniques (Clark, Fannon, Song, Randall, \& Bauer, 2000; Hinton, MacFall, \& McCarthy, 1999; Knight \& Nakada, 1998; Ebmeier et al., 1995). These studies support the hypothesis that novelty processing involves a multifocal network with anatomical components in anterior and posterior regions.

There has been little investigation of the specific functional roles of the different neuroanatomic components of the neural system that processes novel events. In general, the frontal component is viewed as primar- ily involved in detecting novel events and mediating the involuntary response of shifting attention to deviant stimuli (Corbetta \& Shulman, 2002; Knight, 1984; Knight \& Nakada, 1998; Knight \& Scabini, 1998). The posterior parietal lobe has been hypothesized to mediate phasic shifts of attention to infrequent novel or target events (Corbetta \& Shulman, 2002; Knight \& Nakada, 1998; Knight \& Scabini, 1998), or to contribute to the "classification process" in which initially uncategorized events are classified into a discrete group of items (e.g., nontarget, novel events) (Friedman, Cycowicz, \& Gaeta, 2001).

Our laboratory has investigated subjects under a condition in which they are asked to direct attention to novel stimuli that are defined as task relevant (Daffner et al., 1999, 2001; Daffner, Mesulam, Calvo, et al., 2000; Daffner, Mesulam, Scinto, et al., 2000). Previous work in our laboratory using this paradigm has suggested

Table 3. Duration and Reaction Times

\begin{tabular}{|c|c|c|c|c|c|c|c|}
\hline \multirow[b]{2}{*}{$\begin{array}{l}\text { Viewing duration: } \\
\text { novels (msec) }\end{array}$} & \multicolumn{2}{|c|}{ Normal Controls } & \multicolumn{2}{|c|}{ Frontal Patients } & \multicolumn{2}{|c|}{ Parietal Patients } & \multirow{2}{*}{$\frac{p \text { Value }^{a}}{.05}$} \\
\hline & 3655 & $(570)$ & $1885^{\dagger \#}$ & $(270)$ & 4280 & (1075) & \\
\hline $\begin{array}{l}\text { Viewing duration: } \\
\text { backgrounds (msec) }\end{array}$ & 1485 & $(300)$ & 1380 & $(215)$ & 1900 & $(198)$ & ns \\
\hline $\begin{array}{c}\text { Ratio of viewing durations: } \\
\text { novels to backgrounds }\end{array}$ & 2.8 & $(.4)$ & $1.4^{\ddagger}$ & $(.1)$ & 2.1 & $(.4)$ & $<.007$ \\
\hline $\begin{array}{l}\text { Viewing duration: } \\
\text { targets (msec) }\end{array}$ & 2664 & $(245)$ & 2990 & $(415)$ & $4220^{\dagger}$ & $(750)$ & $<.05$ \\
\hline $\begin{array}{l}\text { Ratio of viewing durations: } \\
\text { targets to backgrounds }\end{array}$ & 2.2 & $(.2)$ & 2.3 & $(.3)$ & 2.2 & $(.3)$ & $n s$ \\
\hline $\begin{array}{l}\text { Reaction time to } \\
\text { targets (msec) }\end{array}$ & 1360 & $(160)$ & 1415 & $(180)$ & 1740 & $(295)$ & ns \\
\hline Percentage of hits & 96 & (1) & 94 & (4) & 97 & (1) & ns \\
\hline Number of false alarms & 0.35 & $(.13)$ & 2.20 & $(1.76)$ & 0.57 & $(.30)$ & ns \\
\hline
\end{tabular}

Values given are mean $( \pm S E M) ; n s=$ not significant.

${ }^{a}$ Overall analysis across all three groups.

${ }^{\dagger} p<.04$ vs. normal controls.

${ }^{\#} p<.03$ vs. parietal patients.

${ }^{\ddagger} p<.002$ vs. normal controls. 
Figure 4. Viewing duration of novel stimuli $\div$ viewing duration of background stimuli (mean \pm SEM) for controls, parietal patients and frontal patients.

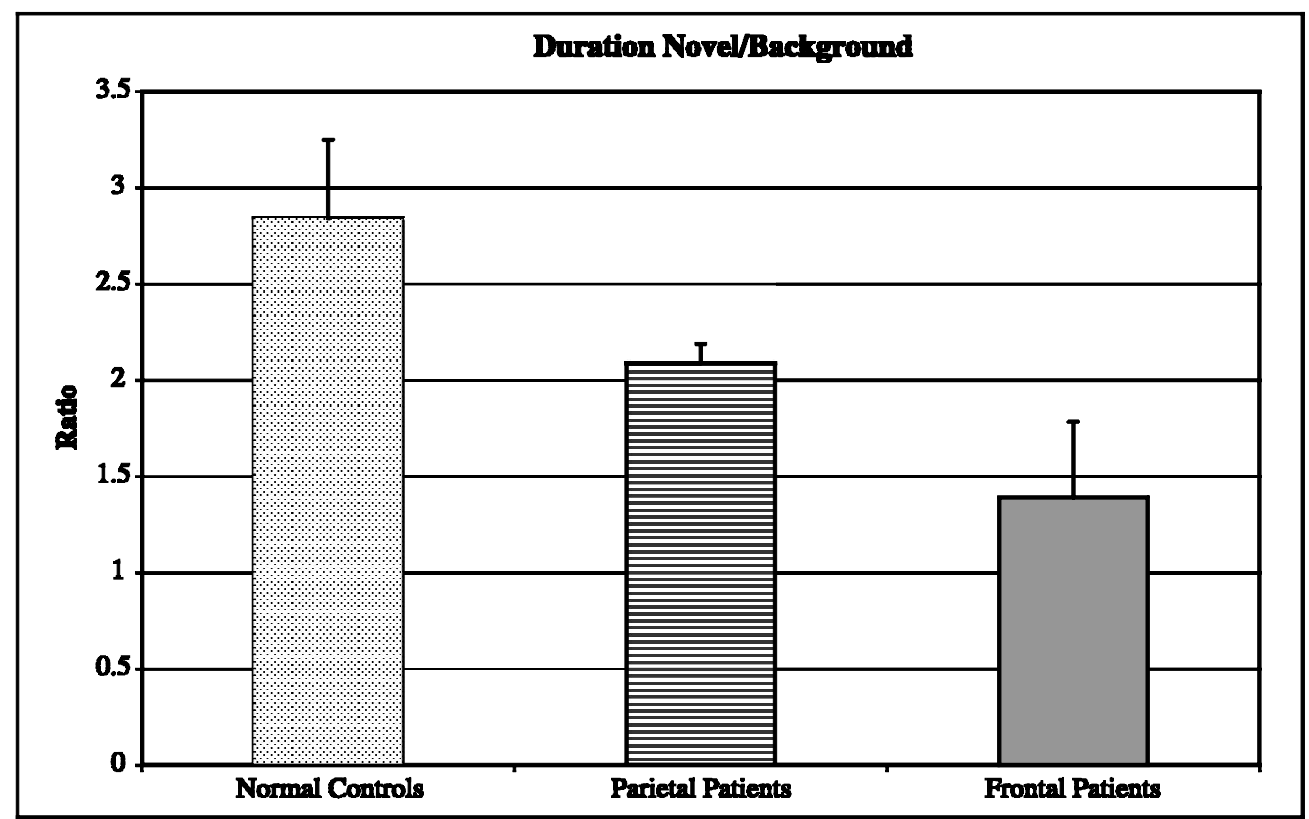

that the novelty $\mathrm{P} 3$ response reflects neural processes that actively allocate attentional resources to potentially significant events in the environment and that the prefrontal cortex is a major component of this novelty processing system (Daffner, Mesulam, Scinto, et al., 2000). In the current study, we have extended this line of investigation by examining the differential impact of focal lesions to anterior and posterior sectors of the brain. Controls, frontal patients, and parietal patients of this study were reasonably well matched in terms of age, estimated IQ, and global cognitive performance, with only small differences in years of education between parietal patients and controls. The patient groups did not suffer from significant problems with language, praxis, or spatially distributed attention. Thus, it is unlikely that these demographic or neuropsychological factors strongly influenced the experimental findings. Frontal patients were the most apathetic group. However, the severity of their apathy was in the mild range and there were no statistically significant differences in

Table 4. Correlations Between Novelty P3 Amplitude and Viewing Durations of Novels Divided by Viewing Durations of Backgrounds

\begin{tabular}{lcc}
\hline \multicolumn{1}{c}{ Subject Group $(s)$} & Spearman's Rho & p Value \\
\hline $\begin{array}{l}\text { Normal controls, } \\
\text { frontal patients, } \\
\text { parietal patients } \\
\text { combined }\end{array}$ & 0.61 & $<0.00001$ \\
Normal controls alone & & \\
Parietal patients alone & 0.54 & $<0.02$ \\
Frontal patients alone & 0.75 & 0.05 \\
\hline
\end{tabular}

apathy severity between frontal and parietal patients, making it less likely that this factor could account for the differences between frontal and parietal patients on the experimental variables. In the past, we have shown a correlation between reduced novelty $\mathrm{P} 3$ amplitude and degree of apathy (Daffner, Mesulam, Scinto, et al., 2000; Daffner et al., 2001). We have suggested that the relationship between apathy and response to novelty is such that diminished engagement by novel aspects of the environment is one mechanism that contributes to the clinical phenomenon of apathy (Daffner, Mesulam, Scinto, et al., 2000; Daffner et al., 2001), rather than apathy being an explanation for reduced attention to novelty.

Our results suggest that both prefrontal and posterior parietal regions participate in the voluntary allocation of attention to novel events and comprise two nodes of a cortical network for responding to and processing novelty. Injury to this network is indexed by reduced novelty $\mathrm{P} 3$ amplitude, which is tightly associated with diminished attention to novel stimuli. The prefrontal and posterior parietal components are likely to be playing different roles in the processing of novel events, which can be elucidated by examining the differential impact of focal damage on responses to novel and target stimuli. Our findings argue against the traditional view of the prefrontal cortex in novelty processing. If, as suggested, the role of the prefrontal cortex were limited to involuntary shifts of attention to and detection of novel events (Knight \& Scabini, 1998) and the posterior parietal regions were capable of participating in similar activity (Corbetta \& Shulman, 2002; Knight \& Scabini, 1998), one would not expect prefrontal damage to have had such a profound impact during a task that emphasized more voluntary aspects of novelty processing, in which subjects had to 
decide how long to look at visual stimuli, including novel ones.

The prefrontal cortex appears to be particularly engaged by stimuli that are ambiguous, for which there is no clear predetermined response (Goldberg, Podell, \& Lovell, 1994; Mesulam, 1986). Consistent with this hypothesis, damage to the prefrontal cortex resulted in a much greater disruption of response to novel stimuli than to designated targets. We found that a reduction of the target P3 response after prefrontal injury was limited to the anterior electrode sites. In contrast, patients with frontal damage exhibited a very widely distributed, profound reduction of the novelty P3 response, suggesting that the prefrontal cortex exerts a controlling influence over additional processing of novel stimuli throughout many regions of the brain. In addition, the peak of the novelty P3 wave was delayed and its duration shortened in frontal patients compared to controls and parietal patients.

These data support the notion that the prefrontal cortex serves as the central node in determining the allocation of attentional resources to novel events. Frontal patients exhibited a reduction of attention directed to novel stimuli (as measured by viewing durations) compared to controls and patients with parietal injury. Furthermore, in all groups that we have studied other than the frontal patients, including normal older subjects, normal younger subjects (Daffner et al., 1998; Daffner, Mesulam, Scinto, et al., 1999), and parietal patients, there has been a strong correlation between the amplitude of the novelty $\mathrm{P} 3$ response and subsequent viewing duration of novel stimuli. In contrast, damage to prefrontal regions abolished this relationship, suggesting that injury to this part of the network leads to a minimal response to novel events, with very little variance across affected individuals.

Our view of the prefrontal cortex as playing a central role in the allocation of attentional resources to novel events, which is indexed by the anterior component of the novelty $\mathrm{P} 3$ response, is consistent with many theories about the relationship between this region of the brain and the functions of the so-called "central executive system" (Smith \& Jonides, 1999; Baddeley, 1992; Stuss \& Benson, 1986) or "supervisory attentional system" (Shallice, 1988). One of the most important functions of this system is the allocation and coordination of attentional processes, which includes determining the extent to which resources are devoted to selected stimuli, inhibiting further allocation of resources to irrelevant stimuli, and modulating the mental effort devoted to processing stimuli.

The responses observed in parietal patients to novel and target stimuli suggest a pattern that differs from that of frontal patients. The parietal lobes appear to be critically involved in the voluntary processing of infrequent stimuli regardless of their degree of novelty. Evidence for this includes the observation that parietal damage is associated with a substantial reduction of both the target P3 and the novelty P3 responses. However, parietal injury leads to a smaller degree of disruption of the processing of novel than of target stimuli. Parietal patients exhibited less overall diminution of the novelty $\mathrm{P} 3$ response, and the reduction observed was more circumscribed to the ipsilesional posterior quadrant. The amplitude of the novelty $\mathrm{P} 3$ response in parietal patients tended to fall between that of controls and frontal patients. Their viewing duration of novel stimuli was not significantly different from that of controls. In contrast, the reduction of target P3 response exhibited by parietal patients was extremely large and very widely distributed.

Compared to the prefrontal cortex, the posterior parietal lobe appears to be more essential for the processing of stimuli previously designated as significant (which in this study were predefined targets) than for the processing of stimuli whose meaning and significance are ambiguous (novel events). This observation is in keeping with the Corbetta-Shulman model of attention that emphasizes the crucial role of parietal cortex in tasks in which stimulus-response associations are simple and can be prepared in advance (Corbetta \& Shulman, 2002). Consistent with the functional neuroimaging literature reviewed by Corbetta and Shulman (2002), prior work with ERPs has suggested that posterior regions coordinate the process of "template matching" (Chao, Nielsen-Bohlman, \& Knight, 1995; Ford \& Otto, 1978; Squires, Hillyard, \& Lindsay, 1973) for stimuli explicitly designated as significant (i.e., targets). However, it is unlikely that the $\mathrm{P} 3$ response is indexing target detection itself, which can occur prior to the onset of the P3 wave (Picton, 1992). Moreover, the detection of targets was successfully achieved by parietal patients in the current study and other investigations (Knight, 1997) despite their having markedly attenuated P3 responses.

In general, the amplitude of the $\mathrm{P} 3$ depends on the infrequency of stimulus presentation, suggesting that it may reflect a fine tuning of expectancies generated by a person's internal model. The multimodal association areas of the parietal lobes have been conceptualized as integrating distributed information to allow for the development of such internal models about the environment (Mesulam, 1981, 1990, 1998). This hypothesized function of the posterior parietal lobe provides an account of the central role it plays in the target P3 response (Donchin, 1981; Donchin \& Coles, 1988). In keeping with this perspective about the parietal lobe, we hypothesize that the posterior component of the novelty P3 may be indexing neural activity involved in updating a highly processed model of the environment to account for a novel event. According to this formulation, the functional role of the posterior component of the novelty P3 would approximate the one frequently hypothesized for the posterior target P3 (Donchin, 1981; 
Donchin \& Coles, 1988). The more that a stimulus is unusual, unexpected, or difficult to integrate into the existing model, the larger the amplitude of the posterior novelty $\mathrm{P} 3$ response.

Many important questions are raised by the current study that will need to be addressed by additional investigation. For example, in what ways do the prefrontal cortex and posterior parietal lobes play different roles in novelty processing under conditions that vary the extent to which a subject's attention is directed toward novel stimuli? We strongly suspect that the scalp distribution of diminished novelty $\mathrm{P} 3$ in frontal patients will be much more extensive under a condition in which subjects are called upon to actively direct attention toward novel stimuli that are task relevant than under conditions in which novel stimuli are defined as task irrelevant and attention is directed away from or only passively toward deviant stimuli. Future studies with larger sample sizes are required to better define which anatomical components of the prefrontal cortex and posterior parietal lobe and which hemisphere make the biggest contribution to responding to novelty.

Additional research also will be necessary to confirm and refine the major conclusion of the current study, which is that both prefrontal and posterior parietal lobes contribute to the voluntary processing of novel events, but that their roles differ. The prefrontal cortex may provide the neural machinery for determining the allocation of attentional resources to novel stimuli, whereas the posterior parietal lobe may provide the neural substrate for the dynamic process of updating one's internal model of the environment to take into account a novel event.

\section{METHODS}

\section{Subjects}

CT or MRI scans of patients with a diagnosis of stroke who were managed by physicians at Brigham and Women's Hospital were reviewed. Two groups of patients were recruited: those whose infarctions were centered in the frontal lobes (with no extension into the parietal cortex) and those whose infarcts were centered in the posterior parietal lobe (with no extension into the frontal cortex). Patients with a history of previous strokes, alcohol abuse, or dementia were excluded. Ten patients with frontal strokes and 8 patients with parietal strokes were recruited. Fifteen patients underwent research MRI scans. Three patients only had CT scans because pacemakers made them ineligible for MRI scans. The experimental (ERP) data from one of the parietal patients was too contaminated by artifact to be informative. Thus, we report on 10 patients with frontal infarctions and 7 patients with parietal infarctions.
Lesion localization was based on the Damasio template system (Damasio \& Damasio, 1989). Six patients had right frontal infarctions; three had left. One patient had suffered small, bilateral frontal infarctions. Infarctions were centered in the prefrontal cortex (Brodmann's areas 45, 46, 9). Six patients had right parietal and one had a left parietal infarct, centered in the posterior parietal cortex around the parietal-temporal junction (Brodmann's areas 39, 40, 22) (Table 5). Because of the variability in the location and size of the cerebral infarctions and the likelihood that they caused direct injury as well as disruption of noninfarcted surrounding tissue, limits are placed on claims about the precise anatomic location of regions damaged or dysfunctional. In this paper, the terms prefrontal and posterior parietal cortex were selected to represent the broad regions of cerebral injury examined. The patient groups did not differ significantly in the median duration post stroke (frontal patients: 18 months vs. parietal patients: 27 months $(p>.1)$. Also, frontal and parietal patients did not differ in the estimated mean lesion size, as measured on Damasio templates by two independent raters (whose interrater correlation was .99).

Normal controls $(n=20)$ were recruited through advertisements in the Boston community. Subjects were excluded if they had a history of cerebrovascular disease, alcohol abuse, dementia, or a focal neurological exam. Informed consent was obtained from all subjects.

Subjects completed the American version of the National Adult Reading Test (Ryan \& Paolo, 1992; Nelson \& O'Connell, 1978) and the Raven's Coloured Progressive Matrices Test (Raven et al., 1995) to determine an estimated IQ score. For controls, the scores on these two tests were averaged, whereas for patients with infarcts, the higher of the two scores was used. Cognitive testing also included the Mini Mental State Examination (Folstein et al., 1975), the naming test of the Multilingual Aphasia Examination (Benton \& DeS.Hamsher, 1983), the Apraxia Examination (Kertesz et al., 1984), and the Line Bisection Test (Schenkenberg et al., 1980) in which subjects had to bisect 18 lines that were displayed across a page. Subjects completed the Apathy Scale (Starkstein et al., 1993, 1995) (a 14-item survey that evaluates a subject's level of interest, motivation, and concern) and the Zung Depression Scale (Zung, 1965) (a 20-item questionnaire about the subject's mood and affective state). Informants who knew the subjects well completed a Personality and Behavioral Inventory (Daffner, Mesulam, Cohen, et al., 1999) that included four items evaluating the subject's degree of apathy by assessing his/her level of initiation, participation, interest, and motivation.

\section{Experimental Procedures}

Three hundred line drawings, white on black background, were presented at the center of a CRT screen. 


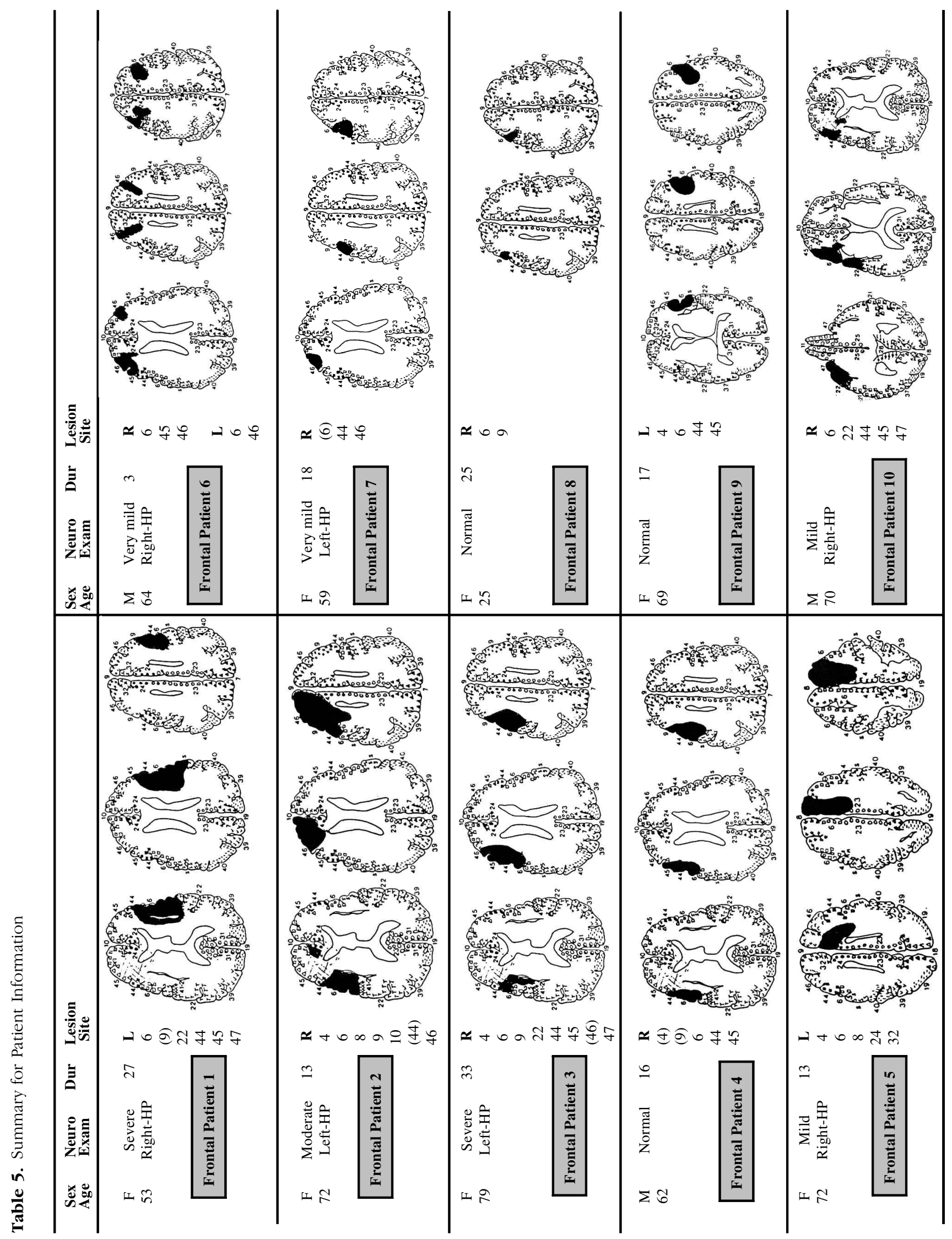




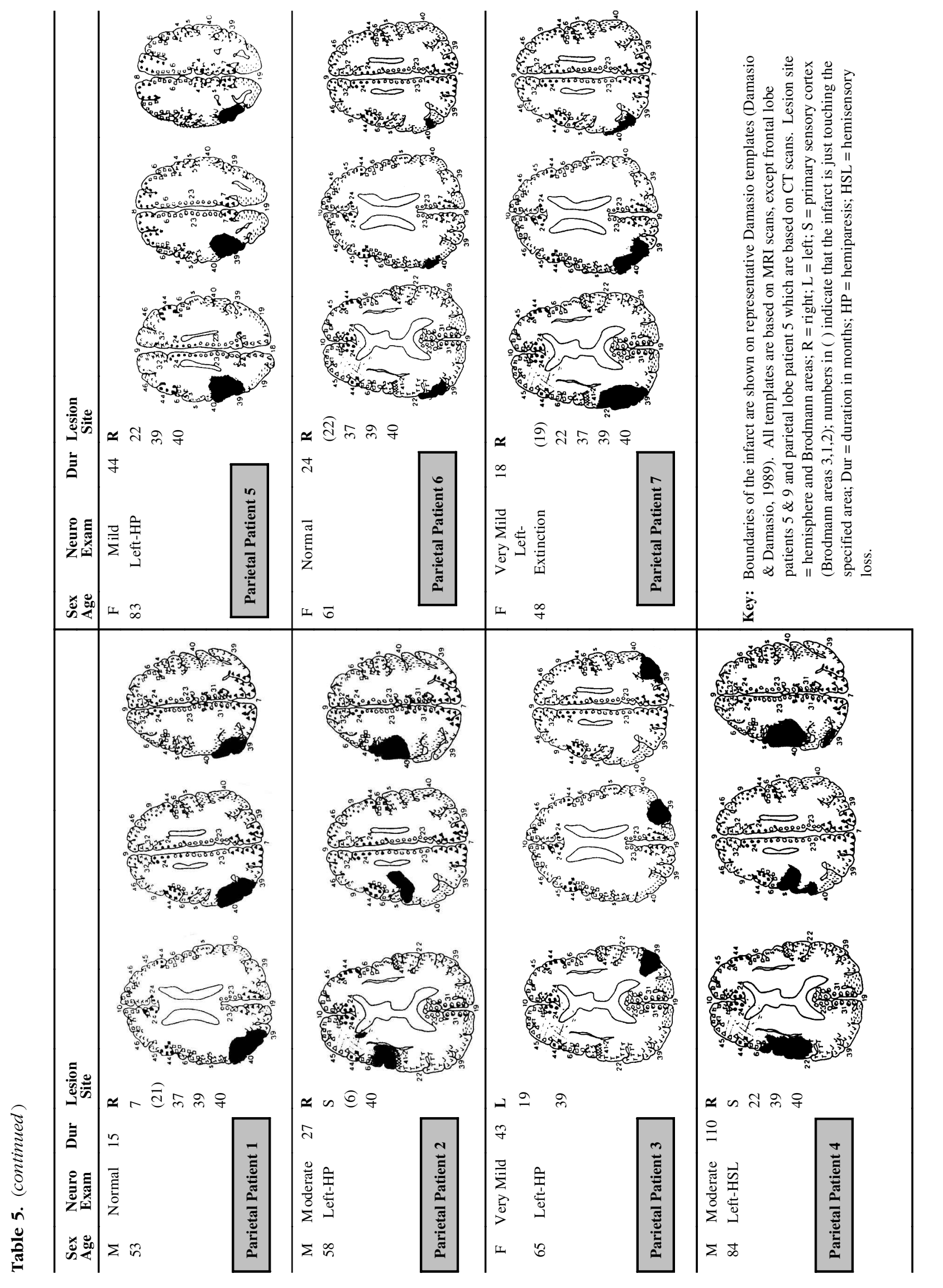


All stimuli subtended a visual angle of approximately $2.75^{\circ}$ along their longest dimension. There were three categories of visual stimuli: (1) a repetitive background stimulus (a triangle)—70\% frequency, (2) target stimulus (upside down triangle)-15\% frequency, and (3) novel stimuli, randomly drawn from a set of unusual/unfamiliar line drawings shown only one time each-15\% frequency. Many of the novel stimuli came from the collection of drawings that have been used by Kroll and Potter (1984) and Kosslyn et al. (1994). Stimuli appeared within a fixation box subtending a visual angle of approximately $3.5^{\circ} \times 3.5^{\circ}$, which remained on the screen at all times. Stimuli were presented in pseudorandom order with the additional constraints that no more than two deviant stimuli were shown consecutively, and that each block of 50 stimuli had the same number of background stimuli and approximately the same number of target and deviant stimuli.

\section{Procedure}

Subjects were informed that the experiment involved the study of brain wave responses as they looked at different kinds of drawings. They were told that they would be looking at a set of drawings and that they could view each picture for however long or short they liked. They controlled the viewing duration by a button press that triggered the onset of the next stimulus. Subjects were told that they would not be asked questions about the pictures at the end of the experiment. Subjects also were told to respond to the designated target stimulus by pressing a foot pedal (ipsilateral to the button press). We called the targets "sequence markers" and indicated to subjects that they were included in the task to help the experimenters keep track of where they were in the sequence of drawings. For the stroke patients, the hand and foot used to respond was ipsilateral to the lesion site. In normal controls and the patient with bilateral frontal lesions, the responding hand/foot was randomly assigned. Although viewing durations were calculated by subtracting the stimulus onset time from the button press time, all stimuli were displayed for a minimum duration of $600 \mathrm{msec}$. The interval between the offset of one stimulus and the onset of the next stimulus ranged between 1 and $1.5 \mathrm{sec}$.

\section{ERP Recordings}

An electrode cap (Electro-Cap International, Eaton, $\mathrm{OH}$ ) was used to hold the 29 active electrodes to the scalp whose locations were based on the International 10-20 system. They included three midline sites (Fz, Cz, Pz) and 26 lateral sites (arranged in four coronal rows from anterior to posterior sites: (a) F7/8, AF7/8, FP1/2; (b) T3/4, FC5/6, F3/4, FC1/2; (c) CP5/6, C3/4, CP1/2; (d) T5/6, $\mathrm{P} 3 / 4, \mathrm{O} 1 / 2)$. All sites were referenced to the left mastoid, and the impedance between each recording site and the reference was reduced to less than $5 \mathrm{k} \Omega$. An electrode was placed beneath the left eye (left mastoid reference) to check for eye blinks and vertical eye movements and another electrode to the right of the subject's right eye (referenced to an electrode to the left of the left eye) to check for lateral eye movements. A final electrode was placed over the right mastoid (referenced to the left) to monitor asymmetrical mastoid activity. None was found.

The EEG was amplified by an SA Instrumentation (San Diego, CA) acquisition system (model H\&W 32BA), using a band filter with negative 3 -dB cutoffs of 0.01 and $40 \mathrm{~Hz}$, and continuously digitized $(200 \mathrm{~Hz})$ by a computer yielding $1280 \mathrm{msec}$ of data from each electrode site, beginning $100 \mathrm{msec}$ before stimulus onset.

\section{Data Analysis}

A continuous record of the raw EEG was stored on hard disk. Offline, EEG epochs for the three stimulus types (background, target, novel) were averaged separately. Trials with eye movements or amplifier blocking were excluded from data analysis. In cases with excessive eye blinks, a blink correction program was employed (Dale, 1994) that computed the impact of the blink on the waveforms in each channel. For the 16 patients with unilateral infarctions, data are presented as a function of electrode site ipsilateral or contralateral to the lesion. In the figures, ERPs ipsilateral to the lesion are shown on the right side of the scalp. The $\mathrm{P} 3$ was defined as the mean amplitude of the wave between 325 and $600 \mathrm{msec}$, measured with respect to the average of the 100-msec prestimulus baseline. (Mean amplitude was chosen over peak amplitude as a way of quantifying the observation that the novelty P3 wave in frontal patients was much narrower than in parietal patients or controls. Of note, the pattern of results found was very similar for mean P3 amplitude and peak P3 amplitude.) P3 latency was defined as the time from stimulus onset to the peak positive wave between 325 and $600 \mathrm{msec}$, as measured at midline sites.

Data were analyzed using repeated measures analysis of variance (ANOVA). There were three levels of group (controls, frontal patients, parietal patients), and for ERP and duration data, three levels of stimulus type (background, target, novel). For ERP measures, there were three midline electrode sites and 13 lateral electrode sites with two levels, one for each hemisphere. Between-group analyses that yielded significant interactions between group, stimulus type, electrode site, or hemisphere resulted in planned contrasts between the levels of the variable. In looking at scalp site interactions with other variables, the data was normalized using a $z$ score technique (Kounios \& Holcomb, 1994) similar to the method recommended by McCarthy and Wood (1985) to avoid problems associated with interpreting site by factor interactions using 
ANOVA. The Geisser and Greenhouse (1959) correction was applied for all repeated measures with greater than 1 degree of freedom.

Data sets involving the behavioral results (e.g., viewing durations, reaction times) or demographic variables that were not normally distributed were transformed (e.g., inverse function) prior to statistical analyses. If assumptions for parametric analyses were still violated, nonparametric statistics (e.g., Mann-Whitney $U$ tests) were employed. Correlation analysis (Spearman's rho) was used to determine the degree of association between novelty P3 amplitude and viewing duration of novel stimuli. All $p$ values reported are two-tailed.

\section{Acknowledgments}

This research was supported in part by NIA grant 1R01 AG017935-01A2. We thank Drs. S. M. Kosslyn, J. F. Kroll, and M. C. Potter for allowing us to use their stimulus sets. We also thank Dr. D. Acar for her helpful input and L. Bliss for her expert administrative assistance.

Reprint requests should be sent to Kirk R. Daffner, Division of Cognitive and Behavioral Neurology, Brigham and Women's Hospital, Harvard Medical School, 221 Longwood Avenue, Boston, MA 02115, U.S.A., or via e-mail: kdaffner@partners.org.

\section{REFERENCES}

Alain, C., Richer, F., Achim, A., \& Saint Hilaire, J. M. (1989). Human intracerebral potentials associated with target, novel, and omitted auditory stimuli. Brain Topography, 1, 237-245.

Baddeley, A. (1992). Working memory. Science, 255, 556-559.

Baudena, P., Halgren, E., Heit, G., \& Clarke, J. M. (1995). Intracerebral potentials to rare target and distractor auditory and visual stimuli: III. Frontal cortex. Electroencephalography and Clinical Neurophysiology, 94 , 251-264.

Benton, A. L., \& DeS.Hamsher, K. (1983). Multilingual aphasia examination. Manual of instructions. Iowa City, IA: AJA Associates.

Berlyne, D. (1960). Conflict, arousal and curiosity. New York: McGraw-Hill.

Chao, L. L., Nielsen-Bohlman, L., \& Knight, R. T. (1995). Auditory event-related potentials dissociate early and late memory processes. Electroencephalography and Clinical Neurophysiology, 96, 157-168.

Clark, V. P., Fannon, S., Song, L., Randall, B., \& Bauer, L. (2000). Responses to rare visual target and distractor stimuli using event-related fMRI. Journal of Neurophysiology, 85, 3133-3139.

Corbetta, M., Kincade, J. M., Ollinger, J. M., McAvoy, M. P., \& Shulman, G. L. (2000). Voluntary orienting is dissociated from target detection in human posterior parietal cortex. Nature Neuroscience, 3, 292-297.

Corbetta, M., \& Shulman, G. L. (2002). Control of goal-directed and stimulus-driven attention in the brain. Nature Reviews Neuroscience, 3, 201-215.

Courchesne, E., Hillyard, S. A., \& Galambos, R. (1975). Stimulus novelty, task relevance and the visual evoked potential in man. Electroencephalography and Clinical Neurophysiology, 39, 131-143.

Craig, A. H., Cummings, J. L., Fairbanks, L., Itti, L., Miller, B. L.,
Li, J., \& Mena, I. (1996). Cerebral blood flow correlates of apathy in Alzheimer's disease. Archives of Neurology, 53, $1116-1120$.

Daffner, K. R., Mesulam, M. M., Calvo, V., Faust, R., Scinto, L. F. M., \& Holcomb, P. J. (2000). An electrophysiological index of stimulus unfamiliarity. Psychophysiology, 37, 737-747.

Daffner, K. R., Mesulam, M. M., Cohen, L. G., \& Scinto, L. F. M. (1999). Mechanisms underlying diminished novelty-seeking behavior in patients with probable Alzheimer's disease. Neuropsychiatry, Neuropsychology, and Behavioral Neurology, 12, 58-66.

Daffner, K. R., Mesulam, M. M., Scinto, L. F. M., Acar, D., Calvo, V., Faust, R., Chabrerie, A., Kennedy, B., \& Holcomb, P. (2000). The central role of the prefrontal cortex in directing attention to novel events. Brain, 123, 927-939.

Daffner, K. R., Mesulam, M. M., Scinto, L. F. M., Calvo, V., Faust, R., West, W. C., \& Holcomb, P. J. (1999). The influence of stimulus deviance on electrophysiologic and behavioral responses to novel events. Journal of Cognitive Neuroscience, 12, 393-406.

Daffner, K. R., Mesulam, M. M., Scinto, L. F. M., Cohen, L. G., Kennedy, B. P., West, W. C., \& Holcomb, P. J. (1998). Regulation of attention to novel stimuli by frontal lobes: An event-related potential study. NeuroReport, 9, 787-791.

Daffner, K. R., Rentz, D., Scinto, L. F. M., Faust, R., Budson, A. E., \& Holcomb, P. J. (2001). Pathophysiology underlying diminished attention to novel events in patients with early AD. Neurology, 56, 1377-1383.

Daffner, K. R., Scinto, L. F. M., Weintraub, S., Guinessey, J., \& Mesulam, M. M. (1992). Diminished curiosity in patients with probable Alzheimer's disease as measured by exploratory eye movements. Neurology, 42, 320-328.

Daffner, K. R., Scinto, L. F. M., Weintraub, S., Guinessey, J., \& Mesulam, M. M. (1994). The impact of aging on curiosity as measured by exploratory eye movements. Archives of Neurology, 51, 368-376.

Dale, A. M. (1994). Source localization and spatial discriminant analysis of event-related potentials: Linear approaches (brain cortical surface). Dissertation Abstracts International, 55-07B, 2559.

Damasio, H., \& Damasio, A. R. (1989). Lesion localization in neuropsychology. New York: Oxford University Press.

Donchin, E. (1981). Surprise! ... surprise? Psychophysiology, 18, 493-513.

Donchin, E., \& Coles, M. G. H. (1988). Is the P300 component a manifestation of context updating? Behavioral and Brain Sciences, 11, 357-374.

Duncan-Johnson, C. C., \& Donchin, E. (1977). On quantifying surprise: The variation in event-related potentials with subjective probability. Psychophysiology, 14, 456-467.

Ebmeier, K. P., Steele, J. D., MacKenzie, D. M., O’Carroll, R. E., Kydd, R. R., Glabus, M. F., Blackwood, D. H. R., Rugg, M. D., \& Goodwin, G. M. (1995). Cognitive brain potentials and regional cerebral blood flow equivalents during two- and three-sound auditory "oddball tasks.' Electroencephalography and Clinical Neurophysiology, 95, 434-443.

Folstein, M. F., Folstein, S. E., \& McHugh, P. R. (1975). "Mini-Mental State." A practical method for grading the cognitive state of patients for the clinician. Journal of Psychiatric Research, 12, 189-198.

Ford, J. M., \& Otto, D. A. (1978). Does P300 reflect template match/mismatch? Multidisciplinary perspectives in event-related brain potential research (pp. 181-183). Washington, DC: EPA.

Friedman, D., Cycowicz, Y. M., \& Gaeta, H. (2001). The novelty P3: An event-related brain potential (ERP) sign of the brain's evaluation of novelty. Neuroscience and Biobehavioral Reviews, 25, 355-373. 
Fuster, J. M. (1989). The prefrontal cortex: Anatomy, physiology, and neuropsychology of the frontal lobe. New York: Raven Press.

Geisser, S., \& Greenhouse, S. (1959). On methods in the analysis of profile data. Psychometrika, 24, 95-112.

Goldberg, E., Podell, K., \& Lovell, M. (1994). Lateralization of frontal lobe functions and cognitive novelty. Journal of Neuropsychiatry and Clinical Neurosciences, 6, $371-378$.

Halgren, E., Baudena, P., Clarke, J. M., Heit, G., Liegeois, C., Chauvel, P., \& Musolino, A. (1995). Intracerebral potentials to rare target and distractor auditory and visual stimuli: I. Superior temporal plane and parietal lobe. Electroencephalography and Clinical Neurophysiology, 94, $191-220$.

Hillyard, S. A., Picton, T. W., Plum, F., Mountcastle, V. B., \& Geiger, S. T. (1987). Electrophysiology of cognition. The handbook of physiology. Section I. The nervous system: Vol. V. Higher functions of the brain part 2 (pp. 519-584). Bethesda, MD: American Physiological Society.

Hinton, S. C., MacFall, J. R., \& McCarthy, G. (1999). Posterior and frontal activation by auditory targets and novel sounds: An event-related functional magnetic resonance imaging study. Neurolmage, 9, S793.

Hunt, J. M., \& Levine, D. (1965). Intrinsic motivation and its role in psychological development. Nebraska symposium on motivation, Vol. XIII (pp. 189-282). Lincoln, NB: University of Nebraska Press.

Johnson, R., Jr. (1986). A triarchic model of P300 amplitude. Psychophysiology, 23, 367-384.

Kertesz, A., Ferro, J. M., \& Shewan, C. M. (1984). Apraxia and aphasia. Neurology, 34, 40-47.

Knight, R. T. (1984). Decreased response to novel stimuli after prefrontal lesions in man. Electroencephalography and Clinical Neurophysiology, 59, 9-20.

Knight, R. T. (1996). Contribution of human hippocampal region to novelty detection. Nature, 383, 256-259.

Knight, R. T. (1997). Distributed cortical network for visual attention. Journal of Cognitive Neuroscience, 9, 75-91.

Knight, R. T., \& Nakada, T. (1998). Cortico-limbic circuits and novelty: A review of EEG and blood flow data. Reviews in the Neurosciences, 9, 57-70.

Knight, R. T., \& Scabini, D. (1998). Anatomic bases of eventrelated potentials and their relationship to novelty detection in humans. Journal of Clinical Neurophysiology, 15, 3-13.

Knight, R. T., Scabini, D., Woods, D. L., \& Clayworth, C. C. (1989). Contributions of temporal-parietal junction to the human auditory P3. Brain Research, 502, 109-116.

Kosslyn, S. M., Alpert, N. M., Thompson, W. L., Chabris, C. F., Rauch, S. L., \& Anderson, A. K. (1994). Identifying objects seen from different viewpoints: A PET investigation. Brain, 117, 1055-1071.

Kounios, J. H., \& Holcomb, P. J. (1994). Concreteness effects in semantic processing: Event-related potential evidence supporting dual-coding theory. Journal of Experimental Psychology: Learning, Memory, and Cognition, 20, 804-823.

Kroll, J. F., \& Potter, M. C. (1984). Recognizing words, pictures, and concepts: A comparison of lexical, object and reality decisions. Journal of Verbal Learning and Verbal Behavior, 23, 39-66.

Loftus, G. R., \& Mackworth, N. H. (1978). Cognitive determinants of fixation location during picture viewing. Journal of Experimental Psychology: Human Perception and Performance, 4, 565-572.

Marin, R. S. (1990). Differential diagnosis and classification of apathy. American Journal of Psychiatry, 147, 22-30.

McCarthy, G., \& Wood, C. C. (1985). Scalp distributions of event-related potentials: Ambiguity associated with analysis of variance models. Electroencephalography and Clinical Neurophysiology, 62, 203-208.

Mecklinger, A., \& Ullsperger, P. (1995). The P300 to novel and target events: A spatio-temporal dipole model analysis. NeuroReport, 7, 241-245.

Mesulam, M. M. (1981). A cortical network for directed attention and unilateral neglect. Annals of Neurology, 10, 309-325.

Mesulam, M. M. (1986). Frontal cortex and behavior. Annals of Neurology, 19, 320-325.

Mesulam, M. M. (1990). Large scale neurocognitive networks and distributed processing for attention, language, and memory. Annals of Neurology, 28, 597-613.

Mesulam, M. M. (1998). From sensation to cognition. Brain, 121, 1013-1052.

Mesulam, M. M. (2000). Behavioral neuroanatomy. Principles of Behavioral and Cognitive Neurology (pp. 1-120). Oxford: Oxford University Press.

Naatanen, R., Gaillard, A. W. K., Gaillard, A. W. K., \& Ritter, W. (1983). The orienting reflex and the N2 deflection of the event-related potential (ERP). Tutorials in ERP research: Endogenous components (pp. 119-141). New York: North-Holland.

Naatanen, R., Picton, T. W., McCallum, W. C., Zappoli, R., \& Denoth, F. (1986). N2 and automatic versus controlled processes. Cerebral psychophysiology: Studies in eventrelated potentials (pp. 169-186). New York: Elsevier.

Nelson, H. E., \& O'Connell, A. (1978). Dementia: The estimation of premorbid intelligence levels using the New Adult Reading Test. Cortex, 14, 234-244.

Picton, T. W. (1992). The P300 wave of the human eventrelated potential. Journal of Clinical Neurophysiology, 9, 456-479.

Posner, M. I., \& Petersen, S. E. (1990). The attention system of the human brain. Annual Review of Neuroscience, 13, 25-42.

Pritchard, W. S., Shappell, S. A., Brandt, M. E., Jennings, J. R., Ackles, P. K., \& Coles, M. G. (1991). Psychophysiology of N200/N400: A review and classification scheme. Advances in psychophysiology, volume 4 (pp. 43-106). London: Jessica Kingsley Publishers.

Raven, J. C., Court, J. H., \& Raven, J. (1995). Coloured progressive matrices, section 2. Manual for Raven's progressive matrices and vocabulary scales (pp. 1-73). Oxford, UK: Oxford Psychologists Press.

Ritter, W., Vaughan, H. G., \& Costa, L. D. (1968). Orienting and habituation to auditory stimuli: A study of short term changes in average evoked responses. Electroencephalography and Clinical Neurophysiology, 25, 550-556.

Rohrbaugh, J. W., Parasuraman, R., \& Davies, D. R. (1984). The orienting reflex: Performance and central nervous system manifestations. Varieties of attention (pp. 323-364). New York: Academic Press.

Roth, W. T. (1973). Auditory evoked responses to unpredictable stimuli. Psychophysiology, 10, 125-138.

Ryan, J., \& Paolo, A. (1992). A screening procedure for estimating premorbid intelligence in the elderly. The Clinical Neuropsychologist, 6, 53-62.

Schenkenberg, T., Bradford, D. C., \& Ajax, E. T. (1980). Line bisection and unilateral visual neglect in patients with neurologic impairment. Neurology, 30, 509-517.

Shallice, T. (1988). From neuropsychology to mental structure. Cambridge: Cambridge University Press.

Shulman, G. L., Ollinger, J. M., Linenweber, M., Petersen, S. E., \& Corbetta, M. (2001). Multiple neural correlates of detection in the human brain. Proceedings of the National Academy of Sciences, U.S.A., 98, 313-318. 
Smith, E. E., \& Jonides, J. (1999). Storage and executive processes in the frontal lobes. Science, 283, 1657-1661.

Snyder, E., \& Hillyard, S. A. (1976). Long-latency evoked potentials to irrelevant, deviant stimuli. Behavioral Biology, 16, 319-331.

Sokolov, E. N. (1963). Higher nervous functions: The orienting reflex. Annual Review of Physiology, 25, 545-580.

Spencer, K. M., Dien, J., \& Donchin, E. (1999). A componential analysis of the ERP elicited by novel events using a dense electrode array. Psychophysiology, 36, 409-414.

Squires, K. C., Hillyard, S. A., \& Lindsay, P. H. (1973). Vertex potentials evoked during auditory signal detection: Relation to decision criteria. Perceptual Psychophysiology, 14, $25-31$.

Squires, N. K., Squires, K. C., \& Hillyard, S. A. (1975).
Two variables of long-latency positive waves evoked by unpredictable auditory stimuli in man. Electroencephalography and Clinical Neurophysiology, 38, 387-401.

Starkstein, S. E., Fedoroff, J. P., Price, T. R., Leiguarda, R., \& Robinson, R. G. (1993). Apathy following cerebrovascular lesions. Stroke, 24, 1625-1630.

Starkstein, S. E., Migliorelli, R., Manes, F., Teson, A., Petracca, G., Chemerinski, E., Sabe, L., \& Leiguarda, R. (1995). The prevalence and clinical correlates of apathy and irritability in Alzheimer's disease. European Journal of Neurology, 2, $540-546$.

Stuss, D. T., \& Benson, D. F. (1986). The frontal lobes. New York: Raven Press.

Zung, W. W. K. (1965). A self rating depression scale. Archives of General Psychiatry, 12, 63-70. 
Copyright of Journal of Cognitive Neuroscience is the property of MIT Press and its content may not be copied or emailed to multiple sites or posted to a listserv without the copyright holder's express written permission. However, users may print, download, or email articles for individual use. 